\title{
Characterization of Cichopeptins, New Phytotoxic Cyclic Lipodepsipeptides Produced by Pseudomonas cichorii SF1-54 and Their Role in Bacterial Midrib Rot Disease of Lettuce
}

\author{
Chien-Jui Huang, ${ }^{1,2}$ Ellen Pauwelyn, ${ }^{1,3}$ Marc Ongena, ${ }^{4}$ Delphine Debois, ${ }^{5}$ Valerie Leclère, ${ }^{6}$ \\ Philippe Jacques, ${ }^{6}$ Peter Bleyaert, ${ }^{3}$ and Monica Höfte ${ }^{1}$ \\ ${ }^{1}$ Department of Crop Protection, Laboratory of Phytopathology, Ghent University, Coupure Links 653, 9000 Ghent, Belgium; \\ ${ }^{2}$ Department of Plant Medicine, National Chiayi University, No. 300, Syuefu Rd., Chiayi City, 60004, Taiwan (R.O.C.); ${ }^{3}$ Inagro \\ vzw, leperseweg 87, 8800 Rumbeke, Belgium; ${ }^{4}$ Walloon Centre for Industrial Biology, University of Liège-Gembloux Agro-Bio \\ Tech, Passage des Déportés 2, 5030 Gembloux, Belgium; ${ }^{5}$ Mass Spectrometry Laboratory (LSM/GIGA-R), Chemistry \\ Department, University of Liege, 4000 Liege, Belgium; ${ }^{6}$ Laboratoire de Procédés Biologiques, Génie Enzymatique et Microbien \\ (ProBioGEM), Université de Lille Sciences et Technologies, 59655 Villeneuve d'Ascq Cedex, France
}

Submitted 24 March 2015. Accepted 1 May 2015.

The lettuce midrib rot pathogen Pseudomonas cichorii SF1-54 produces seven bioactive compounds with biosurfactant properties. Two compounds exhibited necrosis-inducing activity on chicory leaves. The structure of the two phytotoxic compounds, named cichopeptin $A$ and $B$, was tentatively characterized. They are related cyclic lipopeptides composed of an unsaturated C12-fatty acid chain linked to the $\mathrm{N}$ terminus of a 22-amino acid peptide moiety. Cichopeptin B differs from cichopeptin $\mathrm{A}$ only in the last C-terminal amino acid residue, which is probably Val instead of Leu/Ile. Based on peptide sequence similarity, cichopeptins are new cyclic lipopeptides related to corpeptin, produced by the tomato pathogen Pseudomonas corrugata. Production of cichopeptin is stimulated by glycine betaine but not by choline, an upstream precursor of glycine betaine. Furthermore, a gene cluster encoding cichopeptin synthethases, $\operatorname{cip} A B C D E F$, is responsible for cichopeptin biosynthesis. A cipA-deletion mutant exhibited significantly less virulence and rotten midribs than the parental strain upon spray inoculation on lettuce. However, the parental and mutant strains multiplied in lettuce leaves at a similar rate. These results demonstrate that cichopeptins contribute to virulence of $P$. cichorii SF1-54 on lettuce.

Some plant pathogenic Pseudomonas spp., such as $P$. syringae pv. syringae, $P$. fuscovaginae, and $P$. corrugata, produce necrosis-inducing lipopeptide phytotoxins (Bender et al. 1999; Catara 2007; Flamand et al. 1996) that belong to either the syringomycin group or the phytotoxic lipodepsipeptide group, including tolaasin and syringopeptinlike compounds (Gross and Loper 2009; Raaijmakers et al.

Nucleotide sequence data is available in the GenBank database under accession number KJ513094.

Corresponding author: M. Höfte; E-mail: monica.hofte@ugent.be

*The $\boldsymbol{e}$-Xtra logo stands for "electronic extra" and indicates that six supplementary figures and four supplementary tables are published online.

() 2015 The American Phytopathological Society
2006). The members of the syringomycin group are cyclic depsinonapeptides attached to a $\beta$-hydroxy fatty acid tail. Tolaasin and syringopeptin-like compounds are cyclic lipodepsipeptides with a longer and more hydrophobic peptide chain and a higher molecular weight (MW) (Gross and Loper 2009). These two groups of cyclic lipopeptides (CLP) cause cellular lysis by formation of transmembrane pores in the plasma membranes of host cells that lead to disruption of the membrane electrical potential (Brodey et al. 1991; Coraiola et al. 2008; Hutchison et al. 1995). Although these CLP can induce necrosis on plants, phytotoxic CLP contribute to virulence but are not essential for pathogenicity of plant pathogenic pseudomonads (Bender et al. 1999; Scholz-Schroeder et al. 2001).

Biosynthesis of CLP is accomplished via nonribosomal biosynthetic pathways through large multienzyme complexes, nonribosomal peptide synthethases (NRPS), which are encoded by large gene clusters. NRPS have a modular structure in which each module is responsible for the incorporation of one amino acid in the peptide chain. A module consists of a minimal set of three domains: an adenylation domain, a thiolation domain or peptidyl carrier protein domain (PCP), and a condensation domain (Bender et al. 1999; Raaijmakers et al. 2010). Based on the specificity code in the sequence of the A domains of the NRPS modules, the amino acid sequence of the synthesized CLP can be predicted in silico (Challis et al. 2000; de Bruijn et al. 2007; Gross et al. 2007; Stachelhaus et al. 1999).

Pseudomonas cichorii is an important plant-pathogenic bacterium, with a broad host range and a worldwide distribution. $P$. cichorii causes necrotic leaf and stem lesions on many economically important hosts, including lettuce, celery, chrysanthemum, tomato, coffee, and soybean (Bradbury 1986; Jagger 1914; Jones et al. 1984; Wilkie and Dye 1974; Yu and Lee 2012). In Belgium, . cichorii causes midrib rot disease of greenhouse-grown butterhead lettuces (Cottyn et al. 2009, 2011; Pauwelyn et al. 2011). Symptom development on lettuce leaves is strongly associated with apoptosis-like programmed cell death (Kiba et al. 2006, 2009). Intriguingly, the type three secretion system is essential for pathogenicity of $P$. cichorii on eggplant but not on lettuce (Hojo et al. 2008; Kajihara et al. 2012). Production of phytotoxic substances by $P$. cichorii has been described (Hu et al. 1998; Lazzaroni et al. 2003; Pauwelyn 
et al. 2013; Shirakawa and Ozaki 1993), but their role in pathogenicity of $P$. cichorii on lettuce is not clear.

$P$. cichorii SF1-54, which was isolated from diseased butterhead lettuce in Belgium, can produce seven bioactive compounds (named A to $\mathrm{G}$ ) with biosurfactant properties (Pauwelyn et al. 2013). These bioactive compounds differ in inhibition spectra against different microorganisms and in the ability to cause necrosis on chicory leaves (Supplementary Table S1). Compounds D and E, which have been wellidentified, characterized, and renamed cichofactins A and B, are new linear lipopeptides of the syringafactin family and are involved in virulence and surface motility, while compounds B and $\mathrm{C}$ appear to be related to pseudomycins (Pauwelyn et al. 2013). Compounds $F$ and $G$ are phytotoxic molecules and induce necrosis on chicory leaves. Moreover, they have antimicrobial activity against Bacillus megaterium but not against Rhodotorula mucilaginosa. In this study, we attempted to elucidate the structure of the phytotoxic compounds $F$ and $G$ produced by $P$. cichorii SF1-54. A dual approach, which combined chemical characterization by high performance liquid chromatography-electrospray ionization-mass spectrometry (HPLC-ESI-MS) and mining the NRPS-encoding genes in the SF1-54 genome, was used. Furthermore, a mutant deficient in production of cichopeptins was constructed to study the involvement of the phytotoxins in virulence of P. cichorii SF1-54. Our results demonstrate that the phytotoxic CLP are important virulence factors for $P$. cichorii SF1-54 on lettuce. Interestingly, we also found that production of phytotoxic CLP by $P$. cichorii SF1-54 is linked to glycine betaine metabolism.

\section{RESULTS}

\section{Chemical analysis of phytotoxic lipopeptides produced by $P$. cichorii SF1-54 (cichopeptins).}

Compounds $\mathrm{F}$ and $\mathrm{G}$ were purified by reverse phase (RP)HPLC. Based on their phytotoxicity and antimicrobial activity against $B$. megaterium but not against $R$. mucilaginosa, compounds $F$ and $G$ were expected to be new phytotoxic lipodepsipeptides because corpeptin and syringopeptin have similar properties (Emanuele et al. 1998; Lavermicocca et al. 1997).

To structurally characterize the phytotoxic metabolites, HPLC-purified compounds F and G were first submitted to total acid hydrolysis and subsequent HPLC separation of derivatized amino acids. With this methodology, it was not possible to establish a precise quantification of the various amino acids, but 10 different residues with high relative amounts of Ala and Val, more than one Gly, one residue of Ser, Thr, Leu, and Ile, as well as three unidentified amino acids were detected in the purified sample of the molecule. These first results confirm the peptidic nature of compounds $\mathrm{F}$ and $\mathrm{G}$, which were further purified by HPLC-ESI-MS and characterized by ESI-tandem MS (MS/MS). The mass spectrum of purified extract of compounds $\mathrm{F}$ and $\mathrm{G}$ showed two major peaks at $\mathrm{m} / \mathrm{z}, 1,026.1$ and 1,033.1, both doubly charged protonated forms $\left([\mathrm{M}+2 \mathrm{H}]^{2+}\right)$, like syringopeptins (Grgurina et al. 2005; Monti et al. 2001). Based on the $\mathrm{m} / \mathrm{z}$ of the doubly charged protonated ions, the MW of compounds $\mathrm{F}$ and $\mathrm{G}$ were calculated as 2,052.4 and 2,066.2 (exact mass measurements), respectively. Further characterization of the two molecules was obtained by selecting each ion and fragmenting it with argon. Identification of $\mathrm{b}$ and $\mathrm{y}$ " ions reveals very similar fragmentation patterns of the $[\mathrm{M}+\mathrm{H}]^{+}$ions corresponding to compounds F and G (Supplementary Fig. S1; Supplementary Table S2).

The first $b$ ion fragments of compounds $F$ and $G$ were identical and compatible with 2,3-dehydroaminobutyric acid (dhAbu) and a fatty acid moiety that is expected to be a $\mathrm{C}_{12: 1}-\mathrm{OH}$ residue, upon calculation. Thus, the MW difference of 14 between compounds F (MW 2,052.4) and G (MW 2,066.2) can be attributed to a difference in the peptide chain rather than in the fatty acid chain. The first $12 \mathrm{~b}$ ions were the same in the fragmentation spectra of compounds $\mathrm{F}$ and $\mathrm{G}$, indicating a structural identity of the N-terminal part of both molecules, which includes the fatty acid moiety linked to at least 12 amino acid residues. Moreover, the masses of the y" ion fragments obtained from compound G are always 14 Da higher than those of compound F. This difference was maintained until the smallest y" ions that could be detected, at $\mathrm{m} / \mathrm{z} 459.26$ for compound $\mathrm{F}$ and at $\mathrm{m} / \mathrm{z} 473.27$ for compound $\mathrm{G}$. This indicated that the amino acid substitution explaining the 14-Da difference between compounds $F$ and $G$ should occur within the first five residues (discussed below) at the $\mathrm{C}$-terminal end. Further fragmentation of this part of the molecules was not obtained, most probably due to the fact that those residues are involved in the formation of an internal cycle, as occurs in many CLP (Raaijmakers et al. 2006; 2010). Nevertheless, based on those ESI-MS fragmentation data, the putative amino acid sequence of the first 17 amino acids for both compounds $F$ and $G$ could be determined as dhAbu-Pro-Ala-Ala-Ala-Ala-Val-dhAbuGly-Val-Ile-Gly-Ala-Val-Ala-Val-dhAbu. Additionally, according to the spectrophotometric characteristics of both compounds (UV-visible spectrum obtained in diode array-coupled HPLC analysis [data not shown]), no aromatic amino acids are present in the peptide backbone. The proposed peptide structure of the fatty acid chain and the first 17 amino acids of the peptide chain, with their site of cleavage yielding b- and y"-type ions, are presented in Supplementary Fig. S2.

The complete peptide sequences of the two lipopeptides F and $\mathrm{G}$ could not be fully elucidated from these MS/MS analyses due to the high stability of the cyclic substructure involving the last five amino-acids. Multiple attempts to open the ring by chemical breakdown of the lactone bond $\left(\mathrm{KOH} 2 \mathrm{M}\right.$ at $37^{\circ} \mathrm{C}$ for up to $4 \mathrm{~h}$, triethylamine $14.28 \%, \mathrm{pH}=9,37^{\circ} \mathrm{C}, 4 \mathrm{~h}$ or room temperature overnight) were not successful.

However, based on molecular weights, on amino acid composition, and on previously reported structures of Pseudomonas lipopeptides, the remaining part at the C-terminal region of compound $\mathrm{G}$ could be composed of five amino acid residues, which could be Ala, Leu (or Ile), Ser, $a \mathrm{Thr}$, and an unknown amino acid. This suggests compounds $F$ and $G$ are structural relatives of corpeptins (Emanuele et al. 1998). Therefore, we renamed compounds $\mathrm{G}$ and $\mathrm{F}$ cichopeptins $\mathrm{A}$ and $\mathrm{B}$, respectively, and next, used an in silico approach to determine full peptide sequences.

\section{Sequence analysis}

of cichopeptin synthetase-encoding genes.

Since genes responsible for biosynthesis of phytotoxic CLP in $P$. cichorii have not been reported, we performed genome mining based on the genes of syringopeptin synthetases (Feil et al. 2005; Scholz-Schroeder et al. 2003). First, the genome sequence of $P$. cichorii SF1-54 (Pauwelyn et al. 2013) was compared with the genomes of $P$. syringae pv. syringae $\mathrm{B} 728 \mathrm{a}$ and $P$. syringae pv. tomato DC3000 (Buell et al. 2003; Feil et al. 2005), using the MAUVE program (Darling et al. 2010). Then, BlastN searches using the syringopeptin synthetase gene cluster of $P$. syringae pv. syringae B301D (sypA, sypB, and sypC: AF286216.2) (Scholz-Schroeder et al. 2003) as a query against the SF1-54 genome were performed. This resulted in the identification of a large NRPS gene cluster, spanning a region of 73,057 bp in the P. cichorii SF1-54 genome. The sequence, including the NRPS gene cluster and flanking regions, has been submitted to the GenBank database under accession number KJ513094. The structural organization of this NRPS gene cluster and its flanking genes is represented in Figure 1. 
Six NRPS-encoding open reading frames (ORF) were identified in this gene cluster by the program Glimmer (Delcher et al. 1999). They are referred to as $\operatorname{cipA}, \operatorname{cipB}, \operatorname{cip} C, \operatorname{cipD}$, cipE, and cipF. These six genes, which are 14.71, 9.64, 4.62, $13.01,9.42$, and $21.53 \mathrm{~kb}$ in size, respectively, encode NRPS modules with specific condensation (C), adenylation (A), and thiolation (T) domains (Fig. 1). These genes constitute, together, 22 NRPS modules, which confirms that the lipopeptide produced by $P$. cichorii SF1-54 is composed of 22 amino acids. Hence, the results of sequence analysis strongly suggest that the cip gene cluster is responsible for cichopeptin biosynthesis. The cip gene cluster exhibits two typical features of NRPS genes responsible for biosynthesis of lipopeptides: the presence of an $\mathrm{N}$-terminal $\mathrm{C}$ domain in the first module $(\mathrm{C}$ starter) and a tandem of thioesterase domains at the end of the cip cluster. Moreover, Blast analysis of cichopeptin synthetases revealed that the recently released genome sequence of $P$. cichorii JBC1 has a very similar gene cluster (PCH70_25300, PCH70_25310, and PCH70_25320, accession number CP007039.1) encoding hypothetical peptide synthetases. At the amino acid sequence level, cichopeptin synthetases showed $99 \%$ protein identity with these hypothetical peptide synthetases of $P$. cichorii JBC1.

\section{Analysis of cichopeptin synthetases.}

To predict the peptide sequence of cichopeptins from genome sequencing data, bioinformatics analysis of the A domain of each module of cichopeptin synthetases was performed. The putative peptide sequence of cichopeptins is Thr/dhAbu-ProAla-Ala-Ala-Ala-Val-Thr/dhAbu-Gly-Val-Ile-Gly-Ala-ValAla-Val-Thr/dhAbu-Thr/dhAbu-Ala-Dab-Ser-Leu/Ile/Val (Supplementary Table S3). According to the biochemically determined peptide sequence of cichopeptins, the A domains of the first, eighth, and 17th modules are responsible for specific recognition of dhAbu, and the 18th module recognizes $a \mathrm{Thr}$. The prediction is in full agreement with the peptide sequence determined by MS. Furthermore, it confirms that the unidentified C-terminal region of cichopeptins consists of five amino acid residues. Interestingly, the last module, CipF, is predicted to recognize three amino acids, Leu, Ile, and Val. The difference in molecular weight between Leu/Ile and Val is 14 and that is exactly in agreement with the molecular weight difference between cichopeptin A and B. The peptide sequences of the last five amino acid residues are predicted to be $a$ Thr-Ala-Dab-Ser-Leu/Ile (cichopeptin A) and $a$ Thr-Ala-DabSer-Val (cichopeptin B). The calculated masses of the C-terminal fragments of cichopeptins A and B are $18 \mathrm{Da}$ higher than the masses determined by HPLC-ESI-MS, indicating that one water molecule is lost for cyclization, confirming that cichopeptins A and B are CLP with a C-terminal pentapeptide ring.

In Pseudomonas spp., dual condensation and epimerization (C/E) domains are responsible for generating D-amino acids into lipopeptides (Balibar et al. 2005; Rausch et al. 2007). As Gly and dhAbu are nonchiral monomers, the D/L configuration of other amino acid residues of cichopeptins was investigated by detection of specific signatures via weblogos within DownSeq of each C domain (Caradec et al. 2014). According to the signatures, the $\mathrm{C}$ domains of modules $3-8,11-12,14-17$, and 22 are identified as dual $\mathrm{C} / \mathrm{E}$ domains. Therefore, the following structure of cichopeptins $\mathrm{A}$ and $\mathrm{B}$ is proposed: dhAbu_DPro_D-Ala_D-Ala_D-Ala_D-Ala_D-Val_-dhAbu_Gly_D-Val_DIle_Gly_D-Ala_D-Val_D-Ala_D-Val_dhAbu_D-aThr_L-Ala_ L-Dab_D-Ser_L-Leu/Ile and dhAbu_D-Pro_D-Ala_D-Ala_DAla_D-Ala_D-Val_dhAbu_Gly_D-Val_D-Ile_Gly_D-Ala_DVal_D-Ala_D-Val_dhAbu_D- $a$ Thr_L-Ala_L-Dab_D-Ser_L-Val, respectively. The locations of dual $\mathrm{C} / \mathrm{E}$ domains of cichopeptin synthetases are identical to those of syringopeptin synthetases, according to in silico analysis. Furthermore, the specific signature detection confirms that the first $\mathrm{C}$ domain is a $\mathrm{C}$ starter allowing the condensation with the lipidic moiety.

\section{Analysis of the cip flanking sequences.}

Immediately downstream of the cip gene cluster encoding the cichopeptin synthetases, an ABC transporter system (99\% protein identity with $P$. cichorii JBC) as well as a LuxR transcriptional regulator (100 and $57 \%$ protein identity with $P$. cichorii JBC1 and $P$. syringae pv. japonica M301072PT, respectively) have been identified in the genome of $P$. cichorii SF1-54 (Fig. 1). The peptide sequences of the two ABC
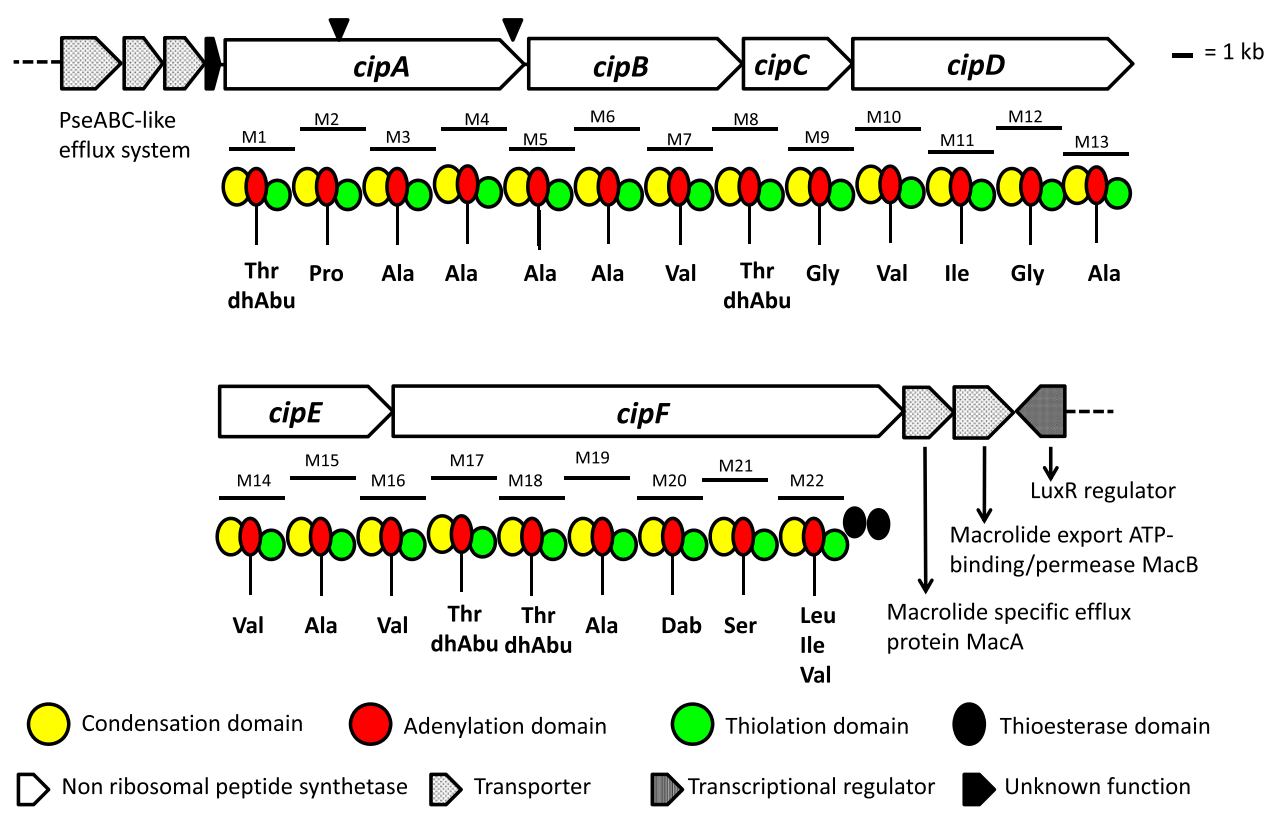

Fig. 1. Schematic representation of the gene cluster involved in biosynthesis of cichopeptin and the surrounding open reading frames in the Pseudomonas cichorii SF1-54 genome. The module and domain organization is indicated below the $\operatorname{cipA}, \operatorname{cip} B, \operatorname{cip} C$, $\operatorname{cipD}$, cipE, and $\operatorname{cip} F$ genes. Predicted amino acid specificity is presented below each module and all amino acids are identified by standard three-letter biochemical notation. Dab $=2,4$-diaminobutyric acid; $\mathrm{dhAbu}=2,3$-dehydroaminobutyric acid. The region between arrowheads was deleted in the cichopeptin-deficient mutant. 
transporter components showed $72 \%$ protein identity with the macrolide efflux protein encoded by macA of the orfamide gene cluster of Pseudomonas fluorescens Pf-5 (PFL_2148) and 81\% protein identity with the macrolide efflux protein encoded by $m a c B$ of the syringopeptin gene cluster of $P$. syringae pv. syringae B728a (Psyr_2618), respectively. Upstream of the cichopeptin synthetase genes, three genes are present that encode proteins exhibiting amino acid homology of $100 \%$ to proteins encoded by PCH70_25250 and PCH70_25260 and of 99\% to PCH70_25270-encoded protein of P. cichorii JBC1. These three proteins also showed homology of $65 \%$ to PseA, $60 \%$ to PseB, and $72 \%$ to PseC. The PseABC efflux system is a tripartite resistance-nodulation-cell division (RND) transporter system, identified at the left border of the syr-syp genomic island of $P$. syringae pv. syringae B301D, with an important role in secretion of syringomycin and syringopeptin (Kang and Gross 2005). The gene located between the cichopeptin biosynthesis genes and the genes encoding the PseABC efflux system shows $56 \%$ amino acid homology with a putative membrane protein of $P$. corrugata.

\section{Cichopeptin production is stimulated by glycine betaine.}

Culture filtrate obtained from still $\mathrm{SRM}_{\mathrm{AF}}$ medium (Mo and Gross 1991) showed clear phytotoxicity and contained cichopeptin concentrations of $21 \pm 16 \mu \mathrm{g} /$ liter based on calculated data from nine different cultures. Culture filtrates obtained from shaken cultures did not show phytotoxicity. Production of cichopeptins was much lower than that of cichofactins (Pauwelyn et al. 2013) and was easily influenced by culture conditions, revealing that $\mathrm{SRM}_{\mathrm{AF}}$ medium is not optimal for $P$. cichorii to produce cichopeptins. Moreover, we were intrigued by the fact that cichopeptins contain two molecules of glycine and that such high content in glycine is not common in Pseudomonas lipopeptides (Gross and Loper 2009; Raaijmakers et al. 2006).

Glycine is a downstream product of choline metabolism (Supplementary Fig. S3). Choline and glycine betaine are potentially abundant in plant hosts including lettuce (Chen et al. 2013; de Zwart et al. 2003; Zeisel et al. 2003). Genes involved in choline uptake and metabolism are present in the genome of P. cichorii SF1-54 (Supplementary Table S4). Further analysis revealed that $P$. cichorii $\mathrm{SF} 1-54 \mathrm{Nal}^{\mathrm{R}}$ can utilize choline and its breakdown product glycine betaine but not glycine as the sole carbon source supplied to minimal medium under well-aerated conditions (Supplementary Fig. S4A). We further tested the effect of choline and glycine betaine on $P$. cichorii $\mathrm{SF} 1-54 \mathrm{Nal}^{\mathrm{R}}$ growth in $\mathrm{SRM}_{\mathrm{AF}}$ medium under static culture conditions, which were used for lipopeptide production. Various concentrations of choline and glycine betaine were tested, but only glycine betaine could be utilized by $P$. cichorii under static culture conditions in $\mathrm{SRM}_{\mathrm{AF}}$ medium. Among all conditions tested, $P$. cichorii exhibited the best growth in $\mathrm{SRM}_{\mathrm{AF}}$ medium containing $10 \mathrm{mM}$ glycine betaine until $72 \mathrm{~h}$ of incubation. In contrast, addition of choline caused an inhibitory effect on $P$. cichorii growth under static culture conditions. Thus, we decided to examine the effect of glycine betaine on cichopeptin production by $P$. cichorii $\mathrm{SF} 1-54 \mathrm{Nal}^{\mathrm{R}}$. Supplementation of glycine betaine at a final concentration of $10 \mathrm{mM}$ in $\mathrm{SRM}_{\mathrm{AF}}$ medium greatly enhanced cichopeptin production by $P$. cichorii SF1-54Nal ${ }^{\mathrm{R}}$ (1.3 and 3.0 fold increases for cichopeptins $A$ and $\mathrm{B}$, respectively) (Fig. $2 \mathrm{~A}$ to $\mathrm{C}$ ). Production of those lipopeptides also reached similar levels by supplementation of glycine betaine at a higher $(1 \%$ or $85 \mathrm{mM})$ concentration (Supplementary Fig. S5). Addition of $1 \mathrm{mM}$ glycine betaine could not stimulate cichopeptin production (Fig. 2A to C). In addition, supplementation of glycine betaine also enhanced production of cichofactins and compound $\mathrm{A}$ but not the production of the pseudomycin-like compounds $\mathrm{B}$ and $\mathrm{C}$ (Fig. 2A).

The filtrate obtained from $P$. cichorii $\mathrm{SF} 1-54 \mathrm{Nal}^{\mathrm{R}}$ culture grown in $\mathrm{SRM}_{\mathrm{AF}}$ medium in the presence of $10 \mathrm{mM}$ glycine betaine induced the strongest necrosis on chicory leaves, among all treatments (Figs. 2D to I). The results are in accordance with the results of cichopeptin production determined by HPLC-ESI-MS analysis (Figs. 2A to C).

\section{In planta fate of cichopeptins produced by $P$. cichorii SF1-54.}

Lettuce tissue inoculated with $P$. cichorii SF1-54 was analyzed using HPLC-ESI-MS to determine lipopeptide production of $P$. cichorii SF1-54 in planta. Cichopeptins were detected at $24 \mathrm{~h}$ postinfiltration in amounts of $4.1 \pm 1.5 \mathrm{ng}$ per gram of leaf fresh weight, while at $48 \mathrm{~h}$ postinoculation, no cichopeptin was detected in infected lettuce tissue. In addition to cichopeptins, cichofactins, which are involved in swarming motility of $P$. cichorii, were detected at each time point. In addition, no trace of compounds $\mathrm{A}, \mathrm{B}$, and $\mathrm{C}$ corresponding to other lipopeptides could be detected in infected lettuce tissue (Fig. 3).

Subsequently, we infiltrated lettuce leaves with a culture filtrate of $P$. cichorii SF1-54 to further study the distribution and stability of lipopeptides in lettuce tissue. The concentration of cichopeptins gradually decreased from $4.4 \pm 1.9$ to $3.5 \pm 0.1 \mathrm{ng}$ per gram of leaf fresh weight over $48 \mathrm{~h}$ after infiltration, while the concentration of cichofactins slightly reduced from $6.4 \times 10^{7} \pm 0.4 \times 10^{7}$ to $5.7 \times 10^{7} \pm 0.7 \times 10^{7}$ peak area per gram of leaf fresh weight during the same time course.

\section{The biological role of cichopeptins produced by $P$. cichorii SF1-54.}

To investigate the biological role of cichopeptins and their importance in pathogenicity for $P$. cichorii SF1-54, we constructed a cichopeptin-deficient mutant, SF1-54- $\Delta$ cipA, by deleting an 8,071-bp fragment in the cichopeptin synthetase A-encoding gene cipA (Fig. 1). Cells of both SF1-54Nal ${ }^{\mathrm{R}}$ and mutant SF1-54- $\Delta$ cipA, suspended into a droplet of water on parafilm, caused immediate drop collapse (data not shown), indicating that the mutant still had biosurfactant activity. HPLC-ESI-MS analysis confirmed that SF1-54- $\Delta$ cipA no longer produced cichopeptins (compounds F and G in the chromatogram) but that deletion of the cichopeptin biosynthesis gene did not influence the production of cichofactins A and B (i.e., compounds $\mathrm{D}$ and $\mathrm{E}$ in the chromatogram, which are no longer produced by the cichofactin mutant SF1-54- $\Delta$ cifAB), pseudomycin-like compounds $\mathrm{B}$ and $\mathrm{C}$, and uncharacterized compound A (Fig. 4A).

As shown in Figure 4B, the culture filtrate of SF1-54- $\Delta$ cipA still caused discoloration of chicory tissue, but the symptoms were somewhat different from the necrosis induced by the culture filtrates of SF1-54Nal ${ }^{\mathrm{R}}$ and SF1-54- $\Delta$ cifAB. Furthermore, induction of discoloration and necrosis on chicory leaves by injection with a cell suspension of SF1-54- $\Delta$ cipA was reduced in comparison with the leaves inoculated with SF1$54 \mathrm{Nal}^{\mathrm{R}}$ and the cichofactin-deficient mutant SF1-54- $\triangle$ cifAB (Fig. 4C).

Moreover, SF1-54- $\Delta$ cipA exhibited significantly smaller inhibition zones against $B$. megaterium than the parental strain and SF1-54- $\triangle c$ ifAB (Fig. 5A). Compared with the parental strain, growth inhibition of $B$. megaterium by SF1-54- $\Delta$ cipA was reduced by $45 \%$. The parental strain and mutant did not differ in inhibitory activity against Geotrichum candidum and R. mucilaginosa.

P. cichorii SF1-54Nal ${ }^{\mathrm{R}}$ swarmed outwards from the inoculation point to cover almost the entire plate containing soft Luria Bertani (LB) medium (0.5\% agar) within $24 \mathrm{~h}$. Swarming 
behavior of the cichopeptin-deficient mutant was identical to the parental strain, while the cichofactin mutant completely lost this ability, indicating that cichofactins but not cichopeptins contribute to swarming activity of $P$. cichorii SF1-54 (Fig. 5B and C).
When lettuce leaves were infiltrated with strains SF1-54Nal ${ }^{\mathrm{R}}$ or SF1-54 $\triangle$ cifAB, cell collapse was observed in almost all of the infiltrated areas at 1 day postinoculation (Supplementary Fig. S6). When lettuce leaves were infiltrated with SF1-54 $\Delta$ cipA,
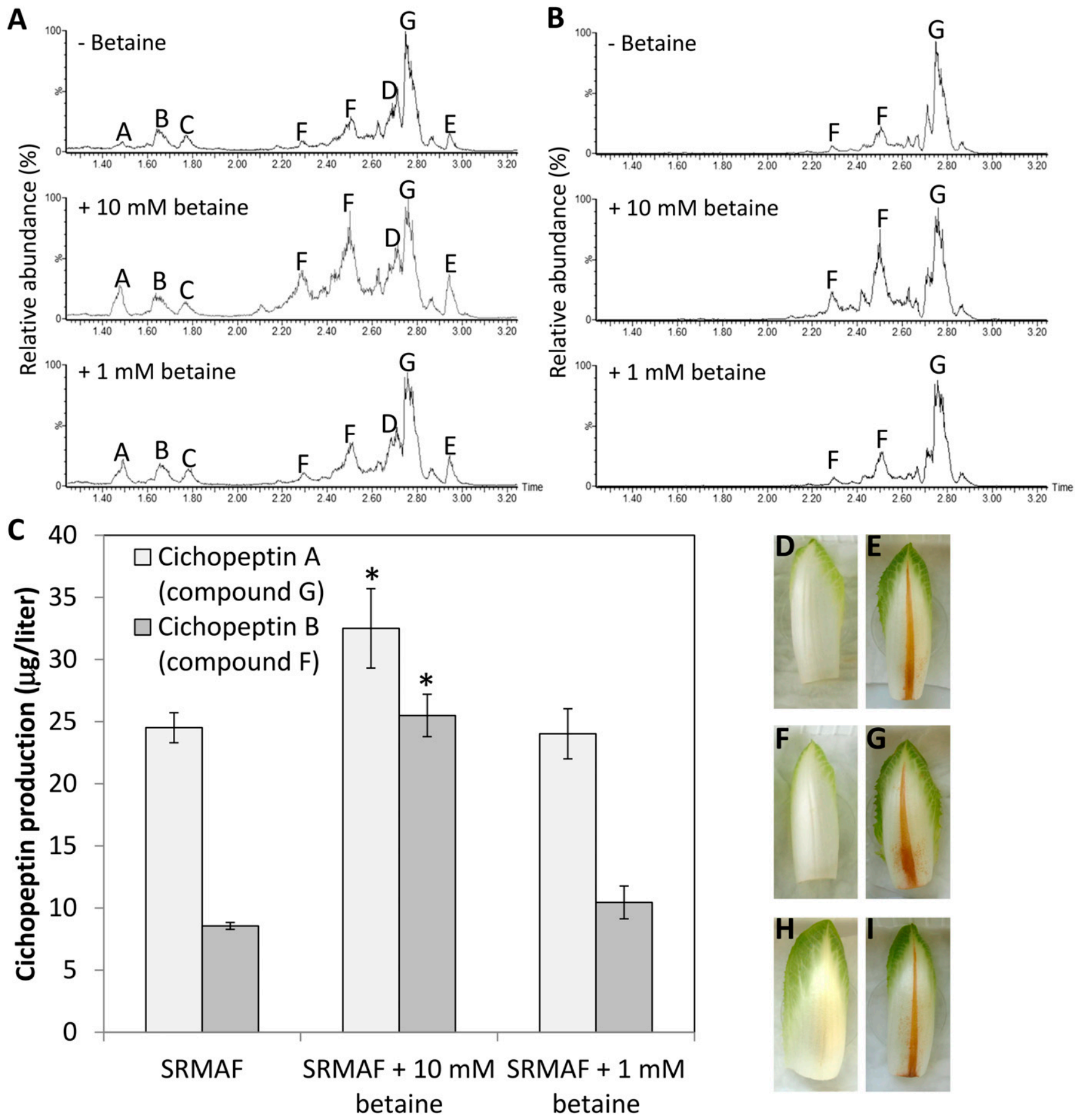

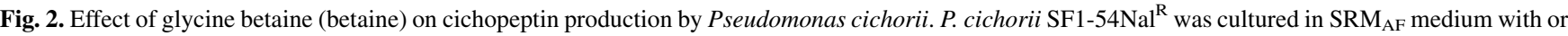
without betaine (1 or $10 \mathrm{mM})$ and the culture filtrates were analyzed by reverse phase ultra-performance liquid chromatography coupled with electrospray ionization mass spectrometry (UPLC-ESI-MS) and by phytotoxicity assay. A, Chromatogram of semipurified extracts of SF1-54Nal ${ }^{\mathrm{R}}$. B, Extracted ion chromatogram of semipurified extracts of SF1-54Nal ${ }^{\mathrm{R}}$, using masses of the most abundant ions of compounds $\mathrm{F}$ and $\mathrm{G}$ (at $m / z 1,027$ and $\mathrm{m} / \mathrm{z} 1,034$, respectively). The $y$ axes of liquid chromatography-mass spectrometry traces are linked at the same scale for comparison of lipopeptide production. Compounds $\mathrm{F}$ and $\mathrm{G}$ are cichopeptins $\mathrm{B}$ and $\mathrm{A}$, respectively. Two peaks labeled $\mathrm{F}$ at different retention times correspond to compounds with the same mass but which probably slightly differ in the position or stereoisomery of some amino acids, resulting in distinct chromatographical behaviors. C, Quantification of relative production of cichopeptins by SF1-54Nal ${ }^{\mathrm{R}}$ based on UPLC-ESI-MS data. Values represent the mean \pm standard deviation of three independent cultures. Bars indicated with the asterisk are significantly different, based on Fisher's least significant difference test $(P<0.05)$. D to I, Assays of phytotoxicity of SF1-

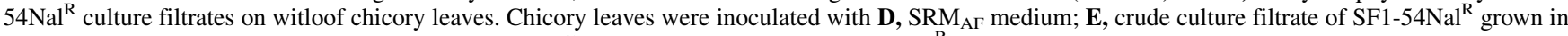

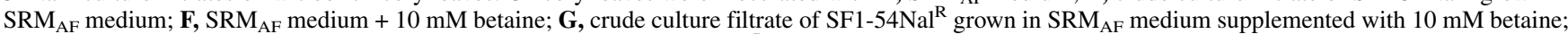
$\mathbf{H}, \mathrm{SRM}_{\mathrm{AF}}$ medium $+1 \mathrm{mM}$ betaine; $\mathbf{I}$, crude culture filtrate of SF1-54Nal ${ }^{\mathrm{R}}$ grown in $\mathrm{SRM}_{\mathrm{AF}}$ medium supplemented with 1 mM betaine. Photographs were taken at 2 days posttreatment. 


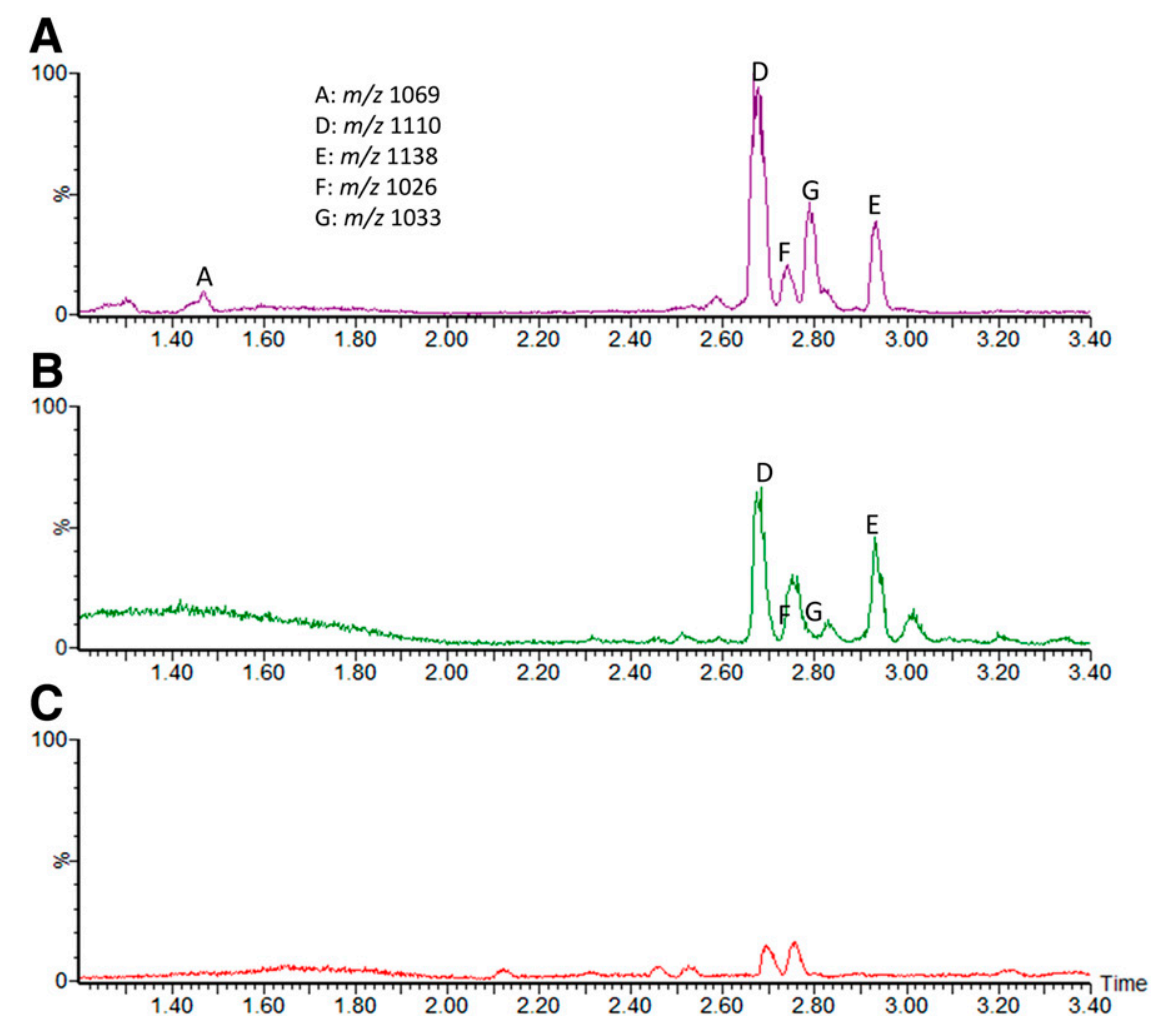

Fig. 3. Liquid chromatography electrospray ionization mass spectrometry detection of Pseudomonas cichorii SF1-54 lipopeptides in A, semipurified extract of P. cichorii SF1-54Nal ${ }^{\mathrm{R}}$ culture filtrate, $\mathbf{B}$, extract of lettuce tissue infected with $P$. cichorii $\mathrm{SF} 1-54 \mathrm{Nal}^{\mathrm{R}}$, and $\mathbf{C}$, extract of mock-inoculated lettuce tissue. Lipopeptides were extracted at $24 \mathrm{~h}$ postinoculation and were analyzed. The $y$ axes of liquid chromatography-mass spectrometry traces are linked at the same scale. Detected lipopeptides in the chromatograms are indicated with a letter. D and E, cichofactins. F and G, cichopeptins. Peaks detected in panel C do not correspond to lipopeptides produced by $P$. cichorii.

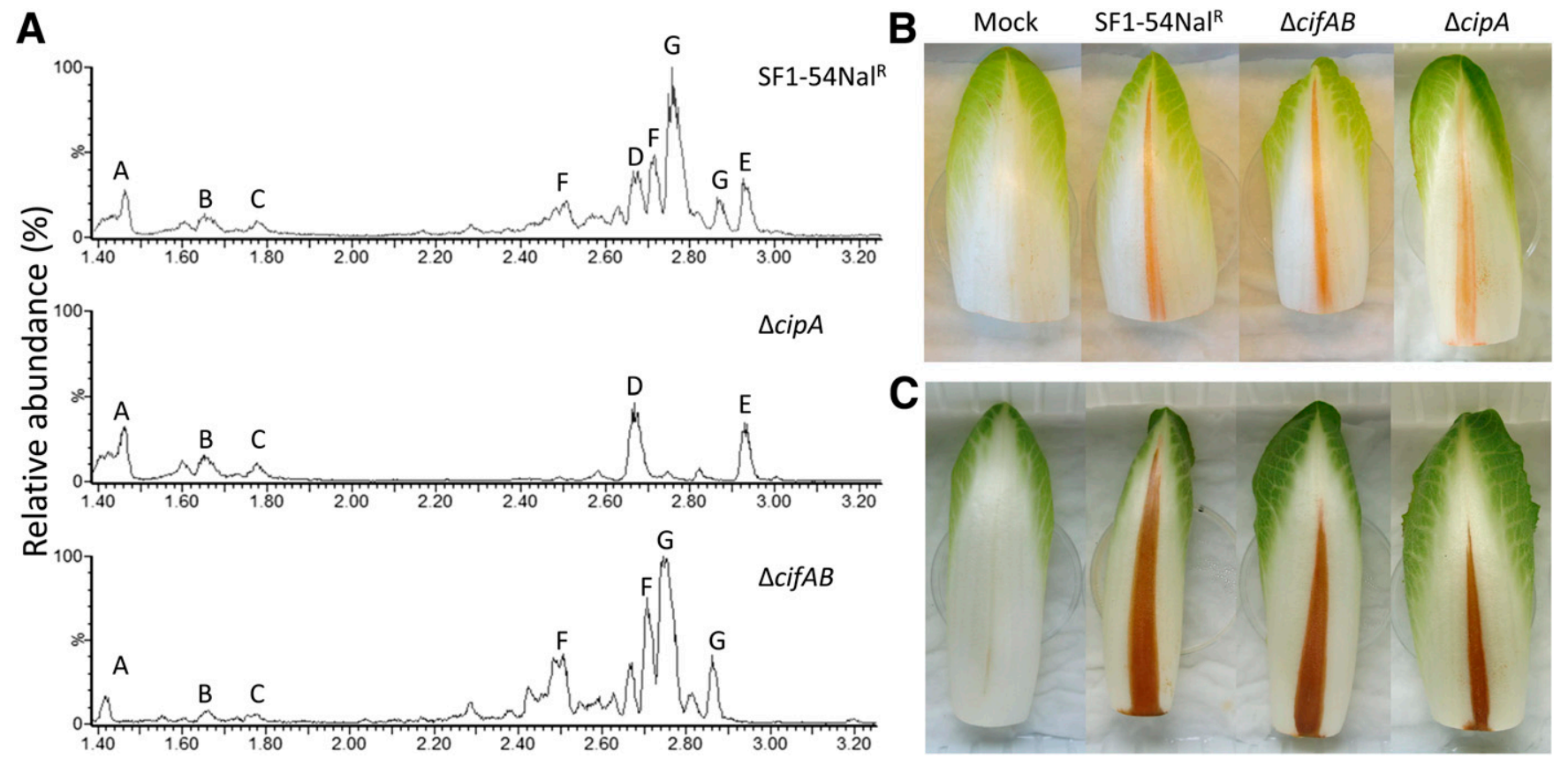

Fig. 4. A, Chromatograms of the semipurified extracts of Pseudomonas cichorii SF1-54Nal ${ }^{\mathrm{R}}$ and its lipopeptide-deficient mutants. Seven bioactive compounds in the semipurified culture extracts were identified by electrospray ionization mass spectrometry analysis. Seven bioactive compounds are indicated with a letter. D and E, cichofactins; F and G, cichopeptins. In addition to the various forms of cichopeptin B, two cichopeptin A forms (peaks labeled G) were also detected at different retention times. They correspond to compounds differing by $+1 \mathrm{mu}$ for the doubly charged molecular ion $(+2 \mathrm{mu}$ for $\mathrm{b}$ fragment ions) (data not shown) which is most probably explained by a saturated form of the acyl chain in the minor form. The $y$ axes of liquid chromatography-mass spectrometry traces are linked at the same scale for comparison of lipopeptide production. B and C, Symptoms caused by Pseudomonas cichorii SF1-54Nal ${ }^{\mathrm{R}}$ and its lipopeptide-deficient mutants on chicory. B, Chicory leaves were inoculated with bacterial culture filtrates or $\mathbf{C}$, bacterial suspensions. Photographs were taken at 1 (B) and 2 days postinoculation (C). Each treatment has been repeated three times and a picture representative of each of the treatments is shown. 
symptom development was significantly slower than in the other two treatments $(P<0.05)$. The cichopeptin-deficient strains mainly caused brown necrosis on lettuce leaves 1 day postinoculation, while cell collapse was clearly observed in the infiltrated areas 2 days postinoculation.

To investigate the effect of cichopeptins on the virulence of P. cichorii SF1-54, greenhouse-grown butterhead lettuces were spray-inoculated with $P$. cichorii $\mathrm{SF} 1-54 \mathrm{Nal}^{\mathrm{R}}$ and its cichopeptindeficient mutant in greenhouse experiments. The cichofactin mutant strain SF1-54- $\triangle c$ if $A B$ was also included. Lettuce plants inoculated with the cichopeptin-deficient mutant SF1-54- $\triangle$ cipA exhibited a significantly lower number of rotten midribs than lettuce plants inoculated with the parental strain (Fig. 6A). However, plants inoculated with the cichopeptin mutant SF1-54- $\Delta$ cipA or the cichofactin mutant SF1-54- $\triangle$ cifAB did not differ in number of rotten midribs. When lettuce midribs were inoculated with SF1$54 \mathrm{Nal}^{\mathrm{R}}$ and its lipopeptide-deficient mutants, all strains grew vigorously and reached similar population densities (approximataely $1 \times 10^{8} \mathrm{CFU} / \mathrm{cm}^{2}$ ) in the inoculated midribs at 1,2 , and 3 days postinoculation (Fig. 6B).

\section{DISCUSSION}

\section{Structure and bioactivity of cichopeptins.}

Cichopeptin A and B are two structurally related cyclic lipopeptides composed of an unsaturated C12-fatty acid chain linked to the N-terminus of a 22-amino acid peptide moiety. The difference between cichopeptins A and B occurs in the last amino acid residue, which is predicted to be Leu/Ile and Val for cichopeptins A and B, respectively. Because the production of cichopeptin B was lower than that of cichopeptin A when P. cichorii SF1-54 was cultured in $\mathrm{SRM}_{\mathrm{AF}}$ medium, it is suggested that the A domain of the last module of $\mathrm{CipF}$ protein recognizes Leu/Ile more specifically or frequently than Val during the synthesis of cichopeptins. Like other phytotoxic CLP (Gross and Loper 2009; Raaijmakers et al. 2006), cichopeptin contains several noncanonical amino acid residues, Dab and dhAbu, one $a \mathrm{Thr}$, and several Ala and Val (Fig. 7). Cichopeptins are structurally related to corpeptin B (Emanuele et al. 1998). The C-terminal pentapeptide rings of cichopeptins and corpeptin $\mathrm{B}$ are almost identical, but cichopeptins contain $\mathrm{Ala}_{6}, \mathrm{Gly}_{9}, \mathrm{Gly}_{12}$, and $\mathrm{Val}_{14}$ instead of $\mathrm{Val}_{6}, \mathrm{Hse}_{9}, \mathrm{dhAbu}_{12}$, and Ala $_{14}$ in corpeptin B (Fig. 7). The fatty acid chain of corpeptin $\mathrm{B}$ is a cis-3-hydroxy-5-dodecenoate (Emanuele et al. 1998). The configuration of the fatty acid chain in cichopeptins is not clear, since we could not elucidate the exact position of the double bond.

Although structurally related, the bioactivities of cichopeptins and corpeptins are slightly different. Cichopeptins and corpeptins show antimicrobial activity against $B$. megaterium but not against $R$. mucilaginosa (Emanuele et al. 1998; Pauwelyn et al. 2013). Syringopeptins also have the same properties
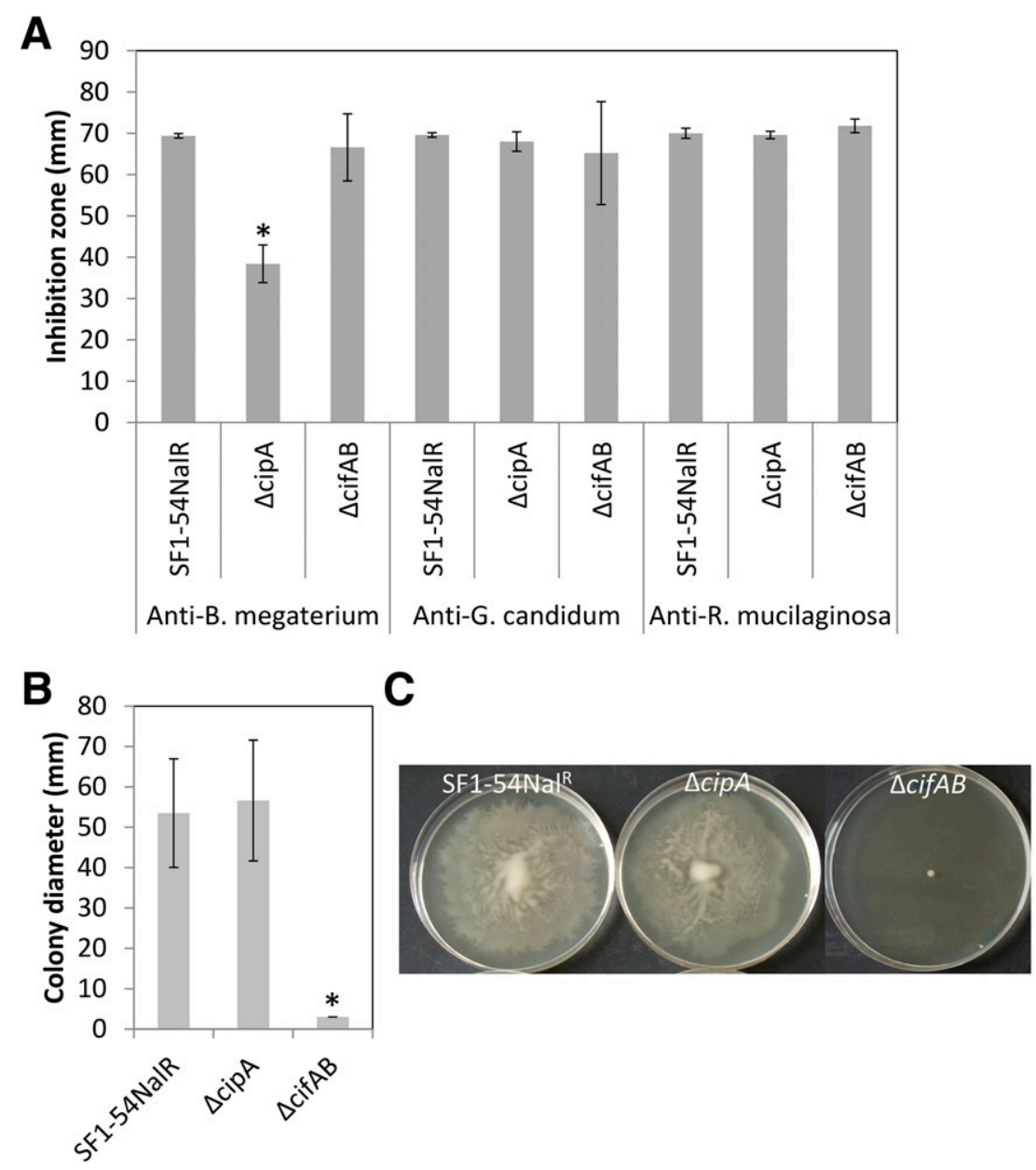

Fig. 5. Phenotypic characterization of lipopeptide-deficient mutants of Pseudomonas cichorii SF1-54NalR. A, Antimicrobial activities of $P$. cichorii SF1$54 \mathrm{NalR}$ and its mutants against three indicator microorganisms. Values represent the mean \pm standard deviation (SD) of five repetitions. B, Swarming activity of $P$. cichorii strains. Values represent the mean $\pm \mathrm{SD}$ of two experiments with four repetitions per experiment. C, Swarming behavior of $P$. cichorii SF1-54 and its mutants on Luria Bertani soft agar $(0.5 \%$ [wt/vol] $)$ plates. Bars indicated with asterisks are statistically different based on nonparametric Kruskal-Wallis and Mann-Whitney comparisons $(P<0.05)$. 
(Lavermicocca et al. 1997). However, phytotoxic lipodepsipeptides showed different levels of phytotoxicity. Chicory leaves treated with purified cichopeptins A or B exhibited clear necrotic symptoms but no chlorosis was observed (Pauwelyn et al. 2013). Infiltration of crude culture filtrate or semipurified extract of $P$. cichorii SF1-54 in tobacco leaves also caused necrosis without symptoms of chlorosis (data not shown). In contrast, both corpeptins $\mathrm{A}$ and $\mathrm{B}$ are chlorosis-inducing cyclic lipodepsipeptides and only corpeptin A can cause necrosis of tobacco leaves (Emanuele et al. 1998). Moreover, fuscopeptin and syringopeptin, two other long lipodepsipeptides with internal cyclization at the $\mathrm{C}$-terminal end, can induce necrosis of plant leaves (Ballio et al. 1996; Iacobellis et al. 1992). Thus, it is suggested that necrosis or chlorosis caused by phytotoxic lipodepsipeptides could be related to these structural traits.

\section{Cichopeptin production by $\boldsymbol{P}$. cichorii is stimulated by glycine betaine.}

We hypothesized that the choline metabolic pathway could be involved in biosynthesis of cichopeptins, because the peptide backbone of cichopeptin contains two residues of glycine, a downstream product of choline metabolism. The choline
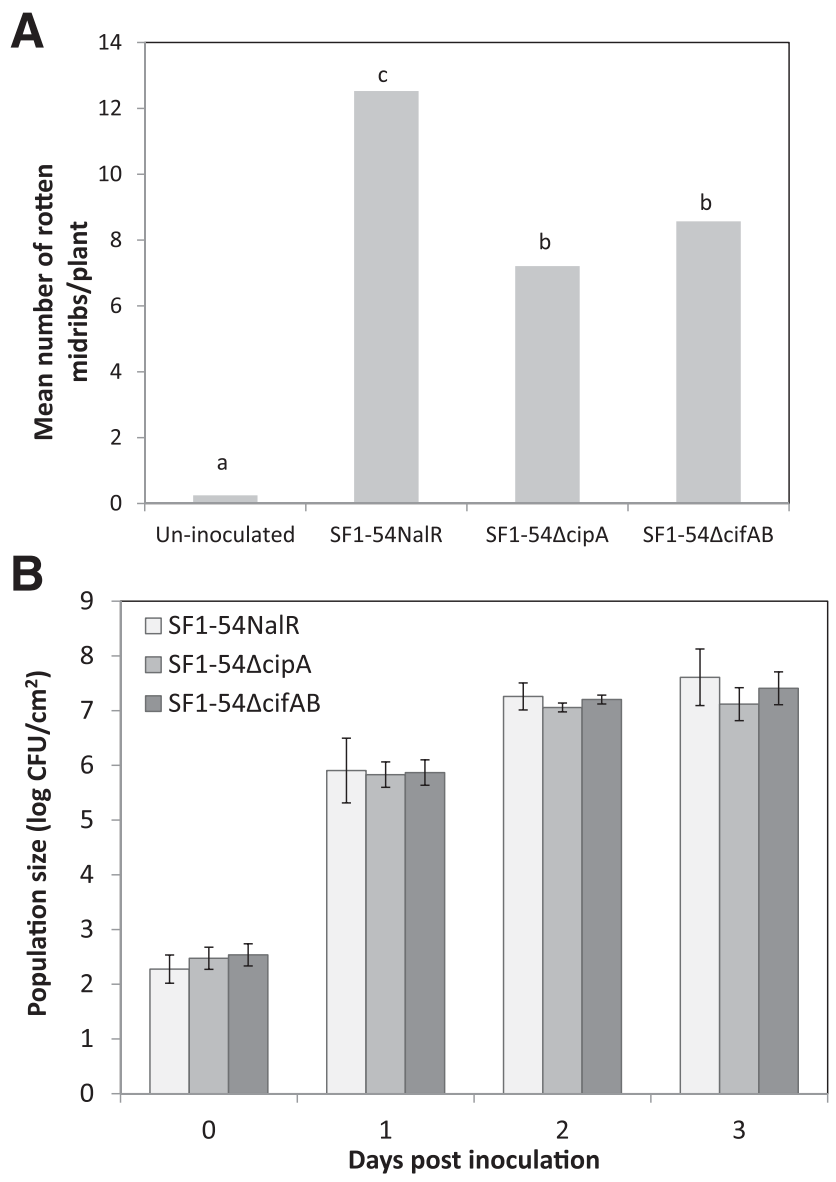

Fig. 6. Effect of cichopeptins on virulence of Pseudomonas cichorii SF154. A, Greenhouse-grown butterhead lettuce plants were inoculated with suspensions of the wild-type or cichopeptin-deficient strains $\left(1 \times 10^{6}\right.$ $\mathrm{CFU} / \mathrm{ml}$ ) after head formation of lettuce. The cichofactin-deficient mutant of $P$. cichorii SF1-54 was also included in the pathogenicity assay. Tap water was used as the uninoculated control. Virulence is represented as mean number of rotten midribs. Bars indicated with the same letter are not statistically different based on nonparametric Kruskal-Wallis and MannWhitney comparisons $(P<0.05)$. B, Population sizes of $P$. cichorii strains in lettuce. Values represent the mean standard deviation of three independent experiments. No significant difference was observed among population sizes of three $P$. cichorii strains in lettuce. catabolic pathway, which is conserved in three model Pseudomonas syringae strains, $P$. syringae pv. phaseolicola $1448 \mathrm{a}$, $P$. syringae pv. syringae $\mathrm{B} 728 \mathrm{a}$, and $P$. syringae $\mathrm{pv}$. tomato DC3000 (Chen and Beattie 2007, 2008; Chen et al. 2013), is also present in $P$. cichorii SF1-54. $P$. syringae can sensitively detect and scavenge choline (the detection limit is $0.1 \mu \mathrm{M}$ ), which is presumably utilized for nutrition or osmoprotection (Chen and Beattie 2007, 2008; Chen et al. 2013). In P. syringae pv. syringae B728a, it has been shown that glycine betaine functions both in nutrition and as an intracellular signal modulating compatible solute synthesis under hyperosmotic stress conditions ( $\mathrm{Li}$ et al. 2013). Although P. cichorii can utilize either choline chloride or glycine betaine as the sole carbon source under well-aerated culture conditions, supplementation of choline chloride and glycine betaine showed opposite effects on $P$. cichorii growth under static culture conditions for lipopeptide production. Addition of choline chloride in $\mathrm{SRM}_{\mathrm{AF}}$ medium showed an inhibitory effect on $P$. cichorii growth when grown statically. In Escherichia coli and Pseudomonas spp., choline is oxidized to glycine betaine via two enzymes, choline dehydrogenase (BetA) and betaine aldehyde dehydrogenase (BetB). The corresponding bet genes require aerobic conditions for their expression (Eshoo 1988; Landfald and Strøm 1986; Wargo 2013) and the growth pattern of static P. cichorii cultures in choline-containing $\mathrm{SRM}_{\mathrm{AF}}$ medium is similar to that of E. coli cultured in choline-containing medium under either fermentative or anaerobic conditions (Landfald and Strøm 1986). Furthermore, betaine aldehyde dehydrogenase is an $\mathrm{NAD}^{+}$-dependent dehydrogenase (Landfald and Strøm 1986; Velasco-García et al. 2000), suggesting that choline catabolism competes for available $\mathrm{NAD}^{+}$with glycolysis and the tricarboxylic acid (TCA) cycle. A pronounced competition for $\mathrm{NAD}^{+}$may occur under static culture conditions, which were used for lipopeptide production by $P$. cichorii in this study. A possible competition for $\mathrm{NAD}^{+}$may also explain the repression of $P$. cichorii growth when statically grown in cholinecontaining $\mathrm{SRM}_{\mathrm{AF}}$ medium compared with $P$. cichorii growth in $\mathrm{SRM}_{\mathrm{AF}}$ medium. On the other hand, inability of choline utilization due to catabolite repression seems less likely, because succinate rather than glucose affects choline utilization by $P$. aeruginosa and $P$. syringae via catabolite repression (Diab et al. 2006; Li et al. 2013). Succinate is not a component of $\mathrm{SRM}_{\mathrm{AF}}$ medium.

Compared with glucose and choline, glycine betaine is a relatively poor carbon source for $P$. cichorii when glycine betaine is the sole carbon source. Surprisingly, however, supplementation of $10 \mathrm{mM}$ glycine betaine significantly enhanced bacterial growth under culture conditions for lipopeptide production and greatly stimulated cichopeptin production by P. cichorii SF1-54 (Fis. 2A to C). Thus, cichopeptin formation appears to be linked to the uptake and catabolism of glycine betaine from the environment. Furthermore, the higher production observed for both cichopeptins upon addition of glycine betaine in the culture medium may result from an increased rate of the TCA cycle resulting from glycine betaine metabolism. The influence of the TCA cycle and amino acid production on lipopeptide production has already been suggested by de Bruijn and Raaijmakers (2009). They demonstrated that the addition of some amino acid residues to the medium partially rescued massetolide production and swarming motility in a $\operatorname{clpP}$ (caseinolytic protease) mutant of strain $P$. fluorescens SS101. It was also suggested that some amino acids may induce NRPS gene transcription (de Bruijn and Raaijmakers 2009), which is also possible for the expression of NRPS-encoding genes in $P$. cichorii.

Cichopeptins were detected in infected lettuce tissue at $24 \mathrm{~h}$ postinoculation but not at $48 \mathrm{~h}$ postinoculation. In the model 
pathosystem Arabidopsis thaliana and P. syringae pv. tomato DC3000, the level of glycine betaine but not choline was significantly elevated in DC3000-challenged Arabidopsis at $12 \mathrm{~h}$ postinoculation (Ward et al. 2010), but the biological impact of this accumulation was not clear. We speculate that $P$. cichorii may trigger accumulation of glycine betaine in lettuce leaves during an early stage of infection. Initially produced cichopeptins (at a relatively low level) may cause membrane disruption by interacting with phospholipid molecules as described for other cyclic lipodepsipeptides (Brodey et al. 1991; Coraiola et al. 2008), resulting in an increased glycine betaine release. The released glycine betaine may be sensed and metabolized by $P$. cichorii for further growth and cichopeptin production.

Another hypothesis is that glycine betaine may play a regulatory role in $P$. cichorii SF1-54. According to a study about the interaction between $P$. syringae pv. syringae $\mathrm{B} 728 \mathrm{a}$ and its native host bean, water was more limited in the leaf interior (apoplast) than on the leaf surface (Yu et al. 2013). Water limitation in the apoplastic sites may result from one or both low water content (e.g., rapid evapotranspiration) or from a high concentration of solutes that is caused by nutrient leakage and secretion in the mesophyll (Yu et al. 2013). Moreover, genes involved in uptake and catabolism of glycine betaine and in biosynthesis and transport of phytotoxic CLP syringomycin and syringopeptin in P. syringae pv. syringae B728a were more strongly induced in apoplastic sites than in epiphytic sites (Yu et al. 2013). Addition of $10 \mathrm{mM}$ glycine betaine to $\mathrm{SRM}_{\mathrm{AF}}$ medium may result in a relatively highosmolality environment, mimicking apoplastic conditions. Further study is necessary to verify whether cichopeptin production is stimulated by increasing osmolality.

In situ persistence of $\boldsymbol{P}$. cichorii-produced lipopeptides.

Our data show the difference in persistence between cichofactin and cichopeptin in infected leaves. When lettuce leaves were infiltrated with $P$. cichorii, severe cell collapse was observed in almost all of the infiltrated areas at $24 \mathrm{~h}$ postinoculation. At the same time point, cichopeptins were clearly detected in infected lettuce tissue (Fig. 3). However, no cichopeptin was detected at $48 \mathrm{~h}$ postinoculation, indicating the importance of cichopeptins at a relatively early stage during pathogenesis of lettuce midrib rot caused by $P$. cichorii. In situ cichopeptin production by $P$. cichorii SF1-54 may be associated with viable lettuce cells because cichopeptin could not detected in completely necrotic lettuce cells. Similar phenomena have been observed in CLP-producing P. fluorescens strains, which exhibit an early phase of CLP production on germinating seeds rather than in bulk soil (Koch et al. 2002; Nielsen and Sørensen 2003; Nielsen et al. 2000). Additionally, it has been shown that germinating sugar beet seeds release unknown compounds that stimulate an early phase production of amphisin and tensin by P. fluorescens strains (Koch et al. 2002; Nielsen and Sørensen 2003; Nielsen et al. 2000). Thus, we suggest that unknown stimulants associated with viable lettuce cells may trigger in situ cichopeptin production by $P$. cichorii SF1-54. On the other hand, cichofactins can be detected up to 5 days postinoculation, suggesting that cichofactin production is not related to viability of lettuce cells. The results are in agreement with our previous study demonstrating that $P$. cichorii SF1-54 can consistently produce cichofactins under various culture conditions (Pauwelyn et al. 2013). The phenomenon of in situ cichofactin production is also reflected in their involvement in the in planta spread of P. cichorii (Pauwelyn et al. 2013).

Furthermore, it was reported that syringomycin produced in plant tissue would be rapidly metabolized into other substances or irreversibly bound (Gross and DeVay 1977). When lettuce leaves were infiltrated with the culture filtrate of $P$. cichorii SF1-54, our data showed that cichofactin was quite stable in lettuce tissue. The concentration of cichopeptin in treated lettuce tissue decreased gradually but not dramatically, indicating that cichopeptin is not prone to degradation or metabolism by lettuce cells. However, we cannot exclude the possibility that cichopeptins might be more susceptible to metabolic degradation in necrotic lettuce tissues than cichofactins during plant pathogenesis. It has been shown that $P$. cichorii triggers apoptosis-like programmed cell death in lettuce that is highly associated with generation of reactive oxygen species and de novo protein synthesis (Kiba et al. 2006, 2009). Reactive oxygen species are able to cause oxidative damage to biomolecules (Halliwell 2006). Alternatively, cichopeptin could be degraded by $P$. cichorii SF1-54 or other microorganisms in

Cichopeptin $\quad \mathrm{R}_{1}$-dhAbu-Pro-Ala-Ala-Ala-Ala-Val-dhAbu-Gly-Val-Ile-Gly-Ala-Val-Ala-Val-dhAbu-aThr-Ala-Dab-Ser-Leu/Ile/Val L

Corpeptin $\quad \mathrm{R}_{2}$-dhAbu-Pro-Ala-Ala-Ala-Val-Val-dhAbu-Hse-Val-Ile-dhAbu-Ala-Ala-Ala-Val-dhAbu-aThr-Ala-Dab-Ser-Ile L

Fuscopeptin $\quad R_{3}$-dhAbu-Pro-Leu-Ala-Ala-Ala-Ala-Val-Gly-Ala-Val-Ala-Val-dhAbu-Dab-aThr-Ala-Dab-Dab-Phe L

Syringopeptin $\mathrm{R}_{4}$-dhAbu-Pro-Val-Val-Ala-Ala-Val-Val-dhAbu-Ala-Val-Ala-Ala-dhAbu- $a$ Thr-Ser-Ala-dhAbu-Ala-Dab-Dab-Tyr

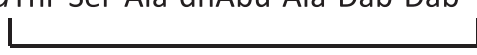

$\mathrm{R}_{1}: \mathrm{COOH}-\mathrm{CH}_{2}-\mathrm{CHOH}-\left(\mathrm{CH}_{2}\right)_{\mathrm{n}}-\mathrm{CH}=\mathrm{CH}-\left(\mathrm{CH}_{2}\right)_{\mathrm{m}}-\mathrm{CH}_{3}$ (cichopeptin A and B)

$\mathrm{R}_{2}$ : 3-hydroxydecanoate (corpeptin $\mathrm{A}$ ); cis-3-hydroxy-5-dodecenoate (corpeptin $\mathrm{B}$ )

$R_{3}$ : 3-hydroxyoctanoate (fuscopeptin A); 3-hydroxydecanoate (fuscopeptin B)

$\mathrm{R}_{4}$ : 2-hydroxydecanoate (syringopeptin 22A); 3-hydroxydodecanoate (syringopeptin 22B)

Fig. 7. Proposed structure of cichopeptin and comparison with structures of corpeptin, fuscopeptin, and syringopeptin SP22. The fatty acid chain of each cyclic lipopeptide is indicated. For cichopeptins, the general formula of the fatty acid chain is presented because the exact location of the double bond was not elucidated. Dab = 2,4-diaminobutyric acid, dhAbu = 2,3-dehydroaminobutyric acid, Hse = homoserine, aThr $=$ allothreonine. The four amino acids that differ between cichopeptin and corpeptin are indicated in bold. 
infected lettuce leaves. It has been suggested that lipopeptides produced by Pseudomonas and Bacillus species are degraded by other microorganisms or the residual producers in nonsterile soil (Asaka and Shoda 1996; Nielsen and Sørensen 2003; Raaijmakers et al. 2010). Apparently, P. cichorii-infected lettuce tissue is a complex environment like nonsterile soil. Further investigations are needed to study the in situ persistence of $P$. cichorii-produced lipopeptides, especially in complex environments.

\section{Cichopeptins are important virulence factors of $\boldsymbol{P}$. cichorii.}

It proved to be very difficult to construct a $\operatorname{cipA}$-deletion mutant of $P$. cichorii SF1-54. We tried three different deletion constructs, two constructs from different locations of $\operatorname{cipA}$ and one construct from $c i p F$, and only the deletion construct described in this study was successfully maintained in $E$. coli. The other two deletion constructs had lethal effects on E. coli, a phenomenon that did not occur when we constructed a cichofactin biosynthesis mutant in our previous study (Pauwelyn et al. 2013). In addition, we obtained cipA mutants showing unexpected phenotypes (e.g., loss of cichofactin production) and several attempts were needed to obtain a cichopeptindeficient mutant that was not affected in the production of cichofactins and the other lipopeptides.

Our data demonstrated that cichopeptins are important for virulence of $P$. cichorii SF1-54 on lettuce. Compared with the parental strain, discolored but not necrotic symptoms were observed on chicory leaves inoculated with the culture filtrate of a cipA-deleted mutant (Fig. 4C). Thus, cichopeptin is an important necrosisinducing factor in culture filtrate. Infiltration with the cipA-deletion mutant, however, still caused necrotic symptoms on chicory and lettuce leaves that cannot visually be differentiated from necrosis induced by the parental strain (Fig. 4). The type three secretion system may be one of the candidate virulence factors for the cichopeptin mutant of $P$. cichorii SF1-54 to cause symptoms on chicory and lettuce. It has been shown that the type three secretion system is not essential for virulence of $P$. cichorii on lettuce (Hojo et al. 2008; Kajihara et al. 2012; Pauwelyn 2012). Thus, it is possible that both cichopeptin and the type three secretion system contribute to $P$. cichorii-induced necrosis in lettuce. We are currently investigating the roles of lipopeptides and type three secretion system in interactions between host plants and P. cichorii SF1-54.
The cichopeptin-deficient mutant of P. cichorii SF1-54 exhibited significantly weaker virulence to butterhead lettuce than the parental strain, but SF1-54- $\Delta$ cipA was as virulent as the cichofactin-deficient mutant (Fig. 6A), indicating that both phytotoxic cichopeptins and motility-related cichofactins affect virulence of $P$. cichorii SF1-54 on lettuce. It should be noticed that production of cichopeptin was not related to bacterial growth in planta (Fig. 6B). Collectively, cichopeptin contributes to induction of necrotic symptoms on lettuces and is a major virulence factor of $P$. cichorii SF1-54, like corpeptin and syringopeptin in the case of $P$. corrugata and $P$. mediterranea (Emanuele et al. 1998; Licciardello et al. 2009, 2012) and P. syringae pv. syringae B301D (Scholz-Schroeder et al. 2001).

In conclusion, we tentatively characterized cichopeptins, the phytotoxic CLP produced by $P$. cichorii SF1-54. Our results demonstrated that cichopeptins contribute to virulence of $P$. cichorii SF1-54 on lettuce and play an important role at the early stages of lettuce infection. We also found that production of cichopeptins by $P$. cichorii SF1-54 is stimulated in the presence of glycine betaine, a compound that can be used for nutrition or functions in signaling osmotic stress.

\section{MATERIALS AND METHODS}

Microorganisms and culture conditions.

Microorganisms used in this study are listed in Table 1. $P$. cichorii SF1-54, its mutants, and $E$. coli strains were stored at $-80^{\circ} \mathrm{C}$ in LB broth (Sambrook and Russel 2001) with $20 \%$ glycerol for long-term storage. $R$. mucilaginosa MUCL 30397, G. candidum MUCL 28959, and B. megaterium LMG 7127 were used as indicator organisms for bioassays of antimicrobial activities. B. megaterium and $R$. mucilaginosa were maintained at $-80^{\circ} \mathrm{C}$ in $\mathrm{LB}$ broth and in potato dextrose broth (Difco, Erembodegem, Belgium) with $20 \%$ glycerol, respectively. G. candidum was maintained on potato dextrose agar (PDA) (Difco) slants. Pseudomonas strains were routinely grown on Pseudomonas agar F (PAF) (Difco) or $\mathrm{SRM}_{\mathrm{AF}}$ (Mo and Gross 1991) medium for production of lipopeptides. B. megaterium and $E$. coli strains were grown on LB medium at 28 and $37^{\circ} \mathrm{C}$, respectively. $R$. mucilaginosa and G. candidum were cultured on PDA at $28^{\circ} \mathrm{C}$. Saccharomyces cerevisiae was grown on yeast

Table 1. Strains, plasmids, and primers used in this study

\begin{tabular}{|c|c|c|}
\hline Strain, plasmid, or primer & Genotype or description ${ }^{a}$ & Source/Reference \\
\hline \multicolumn{3}{|l|}{ Strains } \\
\hline \multicolumn{3}{|l|}{ Pseudomonas cichorii } \\
\hline SF1-54 & Natural isolate from infected greenhouse butterhead lettuce in Belgium & Cottyn et al. 2011 \\
\hline $\mathrm{SF} 1-54 \mathrm{Nal}^{\mathrm{R}}$ & A spontaneous nalidixic acid resistant mutant of $P$. cichorii SF1-54 & Pauwelyn et al. 2013 \\
\hline SF1-54 $\Delta c i f A B$ & A cichofactin-deficient mutant of SF1-54Nal ${ }^{\mathrm{r}}$ & Pauwelyn et al. 2013 \\
\hline SF1-54 cipA & A cipA-deletion mutant & This study \\
\hline Escherichia coli $\mathrm{S} 17-1$ & thi pro hsdR recA::RP4-2-Tc ${ }^{\mathrm{r}}:: \mathrm{Mu} \mathrm{Km}^{\mathrm{r}}:: \mathrm{Tn} 7(\lambda$ pir $), \mathrm{Sm}^{\mathrm{r}}$ & Simon et al., 1983 \\
\hline Bacillus megaterium LMG 7127 & An indicator strain for lipopeptides & \\
\hline Rhodolotula mucilaginosa MUCL 30397 & An indicator strain for lipopeptides & \\
\hline Geotrichum candidum MUCL 28959 & An indicator strain for lipopeptides & \\
\hline Saccharomyces cerevisiae InvSc1 & 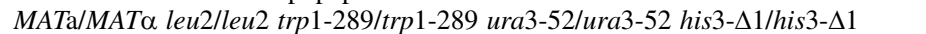 & Invitrogen \\
\hline \multicolumn{3}{|l|}{ Plasmids } \\
\hline pMQ30 & $\begin{array}{l}\text { 7.6-kb mobilizable suicide vector used for gene replacements in } \\
\text { Pseudomonas spp.; SacB, URA3, } \mathrm{Gm}^{\mathrm{r}}\end{array}$ & Shanks et al. 2006 \\
\hline pMQ30-cipA & $\begin{array}{l}\text { pMQ30 containing two approximately } 1-\mathrm{kb} \text { fragments of the cichopeptin } \\
\text { biosynthesis cipA gene to obtain a } 8.1-\mathrm{kb} \text { deletion in the gene }\end{array}$ & This study \\
\hline \multicolumn{3}{|l|}{ Primers $\left(5^{\prime} \rightarrow 3^{\prime}\right)$} \\
\hline CipA-F1 & ccaggcaaattctgttttatcagaccgcttctgcgttctgatGTTGAATCGTCAGGCCAATCG & This study \\
\hline CipA-R1 & GCACCTTCGCCACCATTCAGGTAGATCTCACCCGCAACACCC & This study \\
\hline CipA-F2 & GGGTGTTGCGGGTGAGATCTACCTGAATGGTGGCGAAGGTGC & This study \\
\hline CipA-R2 & ggaattgtgagcggataacaatttcacacaggaaacagctgCCGACACCAACTCCAACGTCG & This study \\
\hline
\end{tabular}

\footnotetext{
${ }^{a}$ Primer extensions are in italic font. $\mathrm{Tc}^{\mathrm{r}}, \mathrm{Km}^{\mathrm{r}}, \mathrm{Sm}^{\mathrm{r}}$, and $\mathrm{Gm}^{\mathrm{r}}$ indicate resistant to tetracycline, kanamycin, streptomycin, and gentamycin, respectively.
} 
extract-peptone-dextrose medium at $30^{\circ} \mathrm{C}$ (Shanks et al. 2006). Antibiotics were added to the growth media (if required) at the following concentrations $(\mu \mathrm{g} / \mathrm{ml})$ : gentamycin, 100 and nalidixic acid, 10.

\section{Chemical analysis of $P$. cichorii SF1-54 lipopeptides.}

Phytotoxic compounds $\mathrm{F}$ and $\mathrm{G}$ were purified from the culture filtrate of $P$. cichorii SF1-54 by RP-HPLC according to the method of Pauwelyn et al. (2013). Purified compounds were used for chemical characterization and structural determination.

Amino acid analysis. For amino acid analysis, HPLCpurified compounds were collected in glass tubes and were dried using vacuum speed (Speed-Vac Plus SC110A; Savant; Thermo Fisher Scientific, Bremen, Germany). The samples were hydrolyzed at $115^{\circ} \mathrm{C}$ for $6 \mathrm{~h}$ in $1.5 \mathrm{ml}$ of $6 \mathrm{~N} \mathrm{HCl}$. After drying in a speedvac (Savant Speed-Vac Plus SC110A) and dissolving in $100 \mu \mathrm{l}$ of $0.1 \mathrm{~N} \mathrm{HCl}$, the samples were analyzed on a ZORBAX Eclipse AAA column (Agilent, Hewlett Packard, Diegem, Belgium), using an Agilent 1100 series HPLC, by strictly following the instructions of the manufacturer. Briefly, the hydrolyzed samples and amino acid standard solutions (purchased from Sigma-Aldrich, Diegem, Belgium) were automatically derivatized in the autosampler with o-phthalaldehyde (OPA) for most amino acids and 9-fluorenylmethyl-chloroformate (FMOC) for lysine, hydroxyproline, and proline residues. After derivatization, $0.5 \mu \mathrm{l}$ of each sample was injected with a flow rate of $2 \mathrm{ml} / \mathrm{min}$ and was detected at 338 (OPA) and $262 \mathrm{~nm}$ (FMOC). Amino acids in the lipopeptide hydrolysis products were identified and their relative amounts in the samples were estimated based on the amino acid standards analyzed simultaneously.

Mass spectrometry. Analysis of lipopeptides produced by P. cichorii SF1-54 was carried out on a LC-ESI-MS (RP-HPLC Waters Alliance 2695/diode array detector in tandem with a Single Quad Waters SQD Mass spectrometer; Waters, Zellik, Belgium) on an XTerra MS C18 Column $(3.5 \mu \mathrm{m}, 4.6 \times$ $150 \mathrm{~mm}$; Waters). Putative lipopeptides of P. cichorii SF1-54 were eluted with a gradient of acetonitrile acidified with $0.1 \%$ formic acid in water acidified with $0.1 \%$ formic acid at a constant flow rate of $0.5 \mathrm{ml} / \mathrm{min}$ at $40^{\circ} \mathrm{C}$. Compounds were monitored in the positive ion mode and in-source settings in the SQD were as follows: source temp, $130^{\circ} \mathrm{C}$; desolvation temp, $280^{\circ} \mathrm{C}$; nitrogen flow, 600 liters/h; cone voltage, $100 \mathrm{~V}$. Similar settings were used for lipopeptide fragmentation, except the cone voltage, which was $75 \mathrm{~V}$ instead of $100 \mathrm{~V}$. Both instruments were controlled with the MassLynx software (Waters). Exact mass measurements and MS/MS experiments were performed with a FT-ICR mass spectrometer (9.4T Solarix; Bruker Daltonics, Bremen, Germany) equipped with an ESI- matrixassisted laser desorption ionization dual ion source including the SmartbeamII laser (wavelength $355 \mathrm{~nm}$ ). Identification of lipopeptides was performed based on mass accuracy, isotopic pattern simulation, and MS/MS. For MS/MS experiments, the selection window in the quadrupole was set to $5 \mathrm{Da}$ and fragmentation was performed in the hexapole, using argon as collision gas and an optimized collision energy of $50 \mathrm{~V}$.

\section{Identification and bioinformatics analysis of the NRPS genes.}

Putative NRPS-encoding regions were found by comparison of the genome sequence of $P$. cichorii SF1-54 (Pauwelyn et al. 2013 ) with the genomes of $P$. syringae pv. tomato DC3000 and $P$. syringae pv. syringae B728a (Buell et al. 2003; Feil et al. 2005), using the program MAUVE (Darling et al. 2010). Gapfilling in the putative NRPS-encoding gene regions was performed by way of polyerase chain reaction (PCR) and Sanger sequencing of PCR products (Agowa Sequencing, Berlin, Germany). ORF were identified using the program Glimmer
(Delcher et al. 1999), available on the National Center for Biotechnology Information website. The catalytic domains present in the NRPS genes were identified using the NRPS/PKS analysis website (Bachmann and Ravel 2009) and the National Institute of Immunology NRPS-PKS website (Ansari et al. 2004). The specificity prediction of the A domain was conducted by using the web-based software NRPSpredictor2 (Rausch et al. 2005; Röttig et al. 2011). The D/L configurations of amino acid residues of nonribosomal peptide synthetases were investigated by phylogenetic analysis of the $\mathrm{C}$ domains via the Phylogeny.fr website (Dereeper et al. 2008) and detection of specific signatures occurring in the DownSeq regions of each C domain (Caradec et al. 2014). Genes adjacent to the putative NRPS genes were compared with the sequences available in GenBank, using the program BlastX. Multiple alignments and phylogeny tree design were performed using ClustalW2 tool available at the European Bioinformatics Institute website.

\section{Growth conditions for enhanced production of cichopeptins.}

Choline chloride, glycine, or glycine betaine (all purchased from Sigma-Aldrich) as the sole carbon source for $P$. cichorii growth were tested. $P$. cichorii $\mathrm{SF} 1-54 \mathrm{Nal}^{\mathrm{R}}$ was cultured in $5 \mathrm{ml}$ of the standard minimal medium (Meyer and Abdallah 1978) containing $1 \%$ of each compound at $28^{\circ} \mathrm{C}$ with shaking at $150 \mathrm{rpm}$. Bacterial growth was measured at $620 \mathrm{~nm}$.

$\mathrm{SRM}_{\mathrm{AF}}$ medium supplemented with various concentrations of choline chloride or glycine betaine was tested for $P$. cichorii growth under static conditions. In a sterile 24-well plate, $1 \mathrm{ml}$ of $\mathrm{SRM}_{\mathrm{AF}}$ medium in the absence or in the presence of choline chloride or glycine betaine was added in a well and a bacterial suspension of $P$. cichorii $\mathrm{SF} 1-54 \mathrm{Nal}^{\mathrm{R}}$ was added in culture media to a final concentration of $1 \times 10^{8} \mathrm{CFU} / \mathrm{ml}$. The plate was sealed with parafilm and was incubated at room temperature as the conditions for lipopeptide production. Bacterial growth was measured at $620 \mathrm{~nm}$.

$\mathrm{SRM}_{\mathrm{AF}}$ medium supplemented with various concentrations of glycine betaine was tested for production of cichopeptin. A bacterial suspension of $P$. cichorii $\mathrm{SF} 1-54 \mathrm{Nal}^{\mathrm{R}}$ was added in culture media ( $25 \mathrm{ml}$ in a $100-\mathrm{ml}$ flask) to a final concentration of $1 \times 10^{8} \mathrm{CFU} / \mathrm{ml}$. Bacterial cultures were incubated at room temperature for 6 days without shaking. After 6 days of incubation, the culture supernatants were collected and filtrated through $0.22-\mu \mathrm{m}$ filters. The cell-free culture filtrates were used for assays of antimicrobial activity and phytotoxicity and HPLCESI-MS analysis. Three independent cultures of each treatment were analyzed and each culture was assayed in triplicate.

\section{In planta detection of lipopeptides produced by $P$. cichorii SF1-54.}

Lettuce leaves were infiltrated with a bacterial suspension of P. cichorii SF1-54Nal ${ }^{\mathrm{R}}\left(1 \times 10^{6} \mathrm{CFU} / \mathrm{ml}\right)$ or a filter-sterilized culture filtrate obtained from $P$. cichorii $\mathrm{SF} 1-54 \mathrm{Nal}^{\mathrm{R}}$ culture grown in $\mathrm{SRM}_{\mathrm{AF}}$ medium. The lettuce leaves were placed on upside down petri dishes into plastic infection trays filled with wetted sterile cotton. The infection trays were covered with a plastic lid to obtain high relative humidity and were incubated at $25^{\circ} \mathrm{C}$. At 24 and $48 \mathrm{~h}$ postinoculation, symptomatic tissue was excised from the lettuce leaves and was ground in liquid nitrogen. After thawing, $1 \mathrm{~g}$ of ground symptomatic leaf tissue was suspended in $3 \mathrm{ml}$ of $50 \%$ acetonitrile, was shaken for $1 \mathrm{~h}$ at room temperature, and was then centrifuged $(5 \mathrm{~min}$ at $10,000 \mathrm{rpm}$ ). Lipopeptides in the supernatants of extractions were concentrated with $\mathrm{C}_{18}$ solid-phase extraction cartridges $\left(\mathrm{C}_{18}\right.$ SPE Maxi-Clean cartridges; Alltech, Grace, Lokeren, Belgium) and were analyzed with LC-ESI-MS. 


\section{Construction of the cichopeptin-deficient}

\section{P. cichorii SF1-54 mutant.}

A cichopeptin-deficient mutant of $P$. cichorii SF1-54Nal ${ }^{\mathrm{R}}$ was constructed by an in vivo cloning technique with the yeast S. cerevisiae InvSc1 (Hoang et al. 1998; Shanks et al. 2006). To construct deletion plasmid pMQ30- $\triangle$ cipA, primers CipA-F1 and CipA-R1 were used to amplify the upstream fragment, and primers CipA-F2 and CipA-R2 for the downstream fragment (Table 1). The cichopeptin-deficient mutant contained a deletion of 8,071 bp in the cichopeptin encoding gene cipA. Deletion of the cipA fragment was confirmed by PCR, and the mutant was characterized phenotypically.

\section{Biological roles of cichopeptin in $\boldsymbol{P}$. cichorii SF1-54.}

Phytotoxic activity was tested on chicory or lettuce leaves by injection of $300 \mu \mathrm{l}$ of bacterial suspension $\left(1.0 \times 10^{8} \mathrm{CFU} / \mathrm{ml}\right.$ in $50 \mathrm{mM}$ phosphate buffer [PB], pH 7.0) or culture filtrate, with a needleless syringe used through the abaxial surface. The infiltrated leaves were incubated at $100 \%$ humidity and $25^{\circ} \mathrm{C}$ for $24 \mathrm{~h}$ and the appearance of necrotic lesions was scored at $24 \mathrm{~h}$ after injection. $\mathrm{PB}$, noninoculated $\mathrm{SRM}_{\mathrm{AF}}$ medium, or $\mathrm{SRM}_{\mathrm{AF}}$ medium supplemented with different carbon sources were used as negative control treatment.

Antimicrobial activity was tested against $B$. megaterium, G. candidum, and Rhodotorula pilimanae, using the protocol described by Pauwelyn et al. (2013). Briefly, bacterial suspensions of $P$. cichorii strains $\left(1 \times 10^{8} \mathrm{CFU} / \mathrm{ml}\right)$ were spotted on PDA plates in five replicates, allowing growth at $25^{\circ} \mathrm{C}$ for 5 days. The areas of colony growth were marked and the colonies were removed with a sterile swab. The plates were exposed to chloroform vapors for $20 \mathrm{~min}$ to kill the remaining bacterial cells, followed by dissipation of the vapors for an additional $40 \mathrm{~min}$. The plate was then sprayed with a spore/cell suspension at a concentration of about $10^{6}$ cells or spores per milliliter of the indicator microorganism. After 24 to $48 \mathrm{~h}$ of incubation at $28^{\circ} \mathrm{C}$, inhibition of the indicator microorganism was scored.

Swarming motility of $P$. cichorii strains was assayed on soft LB plates $(0.5 \%$ agar). Bacteria of a fully grown colony on PAF medium were applied in the center of the soft LB agar plates with a sterile toothpick, and the plates were subsequently incubated at $28^{\circ} \mathrm{C}$ up to $72 \mathrm{~h}$ after inoculation.

To test virulence in detached butterhead leaves, the leaves were inoculated by infiltration with $100 \mu \mathrm{l}$ of a bacterial suspension of each $P$. cichorii strain $\left(5 \times 10^{5} \mathrm{CFU} / \mathrm{ml}\right)$. On one leaf, four sites were inoculated with the same strain. Infiltrated leaves were incubated in humid boxes at $28^{\circ} \mathrm{C}$. Each strain was assayed in triplicate and the experiment was carried out twice. Disease symptoms were evaluated on the inoculated leaves 1 and 2 days postinoculation on a 0 to 3 scale: $0=$ no disease symptoms, 1 = discoloration or small spot of the infiltrated tissue, 2 = brown necrosis of the infiltrated tissue, and $3=$ collapse of the infiltrated tissue. Data were analyzed by the Kruskal-Wallis and Mann-Whitney nonparametric tests $(P=$ 0.05) in SPSS 21.0 for Windows.

Pathogenicity of the lipopeptide-deficient mutants was tested at Inagro, Rumbeke, Belgium, according to the methods described in our previous studies (Pauwelyn et al. 2011, 2013). Butterhead lettuce cv. Hofnar plants (R. Zwaan, De Lier, The Netherlands) at head-formation stage were inoculated with $P$. cichorii strains. Tap water without bacteria was used as the uninoculated treatment. Each treatment was assayed in three replicates, with 24 plants per replicate. At harvest, disease severity was assessed by giving each plant a score ranging from 0 to 4 , in which $0=$ healthy plant, $1=$ little black spots on the leaf periphery of the inner crop leaves, $2=$ infection of small side ribs or black spots or stripes on the midrib, $3=$ one, two or three rotten midribs, and $4=$ four or more rotten midribs. Disease score of all plants was calculated as previously described (Pauwelyn et al. 2011, 2013). All data were statistically analyzed using the software package SPSS 21.0 for Windows. As the data did not meet the conditions of normality and homogeneity of variance, nonparametric Kruskal-Wallis and Mann-Whitney comparisons $(P=0.05)$ were performed.

To test the ability of $P$. cichorii SF1-54 and its mutants to grow in lettuce midribs, the midrib of the inner lettuce leaves was inoculated with $1.0 \mathrm{ml}$ of bacterial suspension $\left(1 \times 10^{5}\right.$ $\mathrm{CFU} / \mathrm{ml}$ ). The inoculated leaves were incubated at $100 \%$ humidity at $25^{\circ} \mathrm{C}$. Nine leaf discs $(1 \mathrm{~cm}$ diameter $)$ were excised from the midribs of three lettuce leaves at $0,1,2$, and 3 days postinoculation and were macerated in $7.0 \mathrm{ml}$ of sterile $50 \mathrm{mM}$ potassium $\mathrm{PB}(\mathrm{pH}$ 7.0). Tenfold serial dilutions from the macerate were prepared with $\mathrm{PB}$, and $100-\mu \mathrm{l}$ aliquots of each dilution were spread on three PAF plates with $50 \mu \mathrm{g}$ of nalidixic acid per milliliter. Colonies were counted 2 days after incubation at $28^{\circ} \mathrm{C}$, to estimate population densities. The experiment was repeated twice. All data were statistically analyzed, using the software package SPSS 21.0 for Windows. As the data did not meet the conditions of normality and homogeneity of variance, nonparametric Kruskal-Wallis and Mann-Whitney comparisons $(P=0.05)$ were performed.

\section{ACKNOWLEDGMENTS}

M. Ongena and D. Debois are research associates at the Fonds de la Recherche Scientific - FNRS in Belgium. This work was financed by the Fund for Scientific Research Flanders (FWO Vlaanderen, grant number G.0002.10N) and by the INTERREG IVa program France-WallonieVlaanderen (Phytobio project). We thank L. Franzil (Gembloux Agro-Bio Tech), I. Delaere (Ghent University), and R. Houthoofd (Inagro) for technical assistance during the experimental work.

\section{LITERATURE CITED}

Ansari, M. Z., Yadav, G., Gokhale, R. S., and Mohanty, D. 2004. NRPSPKS: A knowledge-based resource for analysis of NRPS/PKS megasynthases. Nucleic Acids Res. 32:W405-W413.

Asaka, O., and Shoda, M. 1996. Biocontrol of Rhizoctonia solani dampingoff of tomato with Bacillus subtilis RB14. Appl. Environ. Microbiol. 62: 4081-4085.

Bachmann, B. O., and Ravel, J. 2009. Chapter 8. Methods for in silico prediction of microbial polyketide and nonribosomal peptide biosynthetic pathways from DNA sequence data. Methods Enzymol. 458:181-217.

Balibar, C. J., Vaillancourt, F. H., and Walsh, C. T. 2005. Generation of D amino acid residues in assembly of arthrofactin by dual condensation/epimerization domains. Chem. Biol. 12:1189-1200.

Ballio, A., Bossa, F., Camoni, L., Di Giorgio, D., Flamand, M. C., Maraite, H., Nitti, G., Pucci, P., and Scaloni, A. 1996. Structure of fuscopeptins, phytotoxic metabolites of Pseudomonas fuscovaginae. FEBS (Fed. Eur. Biochem. Soc.) Lett. 381:213-216.

Bender, C. L., Alarcón-Chaidez, F., and Gross, D. C. 1999. Pseudomonas syringae phytotoxins: Mode of action, regulation, and biosynthesis by peptide and polyketide synthetases. Microbiol. Mol. Biol. Rev. 63: 266-292.

Bradbury, J. F. 1986. Guide to plant pathogenic bacteria. Oxford University Press, USA.

Brodey, C. L., Rainey, P. B., Tester, M., and Johnstone, K. 1991. Bacterial blotch disease of the cultivated mushroom is caused by an ion channel forming lipodepsipeptide toxin. Mol. Plant Microbe Interact. 4:407-411.

Buell, C. R., Joardar, V., Lindeberg, M., Selengut, J., Paulsen, I. T., Gwinn, M. L., Dodson, R. J., Deboy, R. T., Durkin, A. S., Kolonay, J. F., Madupu, R., Daugherty, S., Brinkac, L., Beanan, M. J., Haft, D. H., Nelson, W. C., Davidsen, T., Zafar, N., Zhou, L., Liu, J., Yuan, Q., Khouri, H., Fedorova N., Tran, B., Russell, D., Berry, K., Utterback, T., Van Aken, S. E., Feldblyum, T. V., D’Ascenzo, M., Deng, W. L., Ramos, A. R., Alfano, J. R., Cartinhour, S., Chatterjee, A. K., Delaney, T. P., Lazarowitz, S. G., Martin, G. B., Schneider, D. J., Tang, X., Bender, C. L., White, O., Fraser, C. M., and Collmer, A. 2003. The complete genome sequence of the Arabidopsis and tomato pathogen Pseudomonas syringae pv. tomato DC3000. Proc. Natl. Acad. Sci. U.S.A. 100:10181-10186. 
Caradec, T., Pupin, M., Vanvlassenbroeck, A., Devignes, M. D., SmaïlTabbone, M., Jacques, P., and Leclère, V. 2014. Prediction of monomer isomery in Florine: A workflow dedicated to nonribosomal peptide discovery. PLoS ONE 9:e85667.

Catara, V. 2007. Pseudomonas corrugata: Plant pathogen and/or biological resource? Mol. Plant Pathol. 8:233-244.

Challis, G. L., Ravel, J., and Townsend, C. A. 2000. Predictive, structurebased model of amino acid recognition by nonribosomal peptide synthetase adenylation domains. Chem. Biol. 7:211-224.

Chen, C., and Beattie, G. A. 2007. Characterization of the osmoprotectant transporter OpuC from Pseudomonas syringae and demonstration that cystathionine- $\beta$-synthase domains are required for its osmoregulatory function. J. Bacteriol. 189:6901-6912.

Chen, C., and Beattie, G. A. 2008. Pseudomonas syringae BetT is a lowaffinity choline transporter that is responsible for superior osmoprotection by choline over glycine betaine. J. Bacteriol. 190:2717-2725.

Chen, C., Li, S., McKeever, D. R., and Beattie, G. A. 2013. The widespread plant-colonizing bacterial species Pseudomonas syringae detects and exploits an extracellular pool of choline in hosts. Plant J. 75:891-902.

Coraiola, M., Paletti, R., Fiore, A., Fogliano, V., and Dalla Serra, M. 2008. Fuscopeptins, antimicrobial lipodepsipeptides from Pseudomonas fuscovaginae, are channel forming peptides active on biological and model membranes. J. Pept. Sci. 14:496-502.

Cottyn, B., Baeyen, S., Pauwelyn, E., Verbaednert, I., De Vos, P., Bleyaert, P., Hofte, M., and Maes, M. 2011. Development of a real-time PCR assay for Pseudomonas cichorii, the causal agent of midrib rot in greenhousegrown lettuce, and its detection in irrigating water. Plant Pathol. 60: 453-461.

Cottyn, B., Heylen, K., Heyrman, J., Vanhouteghem, K., Pauwelyn, E., Bleyaert, P., Van Vaerenbergh, J., Höfte, M., De Vos, P., and Maes, M. 2009. Pseudomonas cichorii as the causal agent of midrib rot, an emerging disease of greenhouse-grown butterhead lettuce in Flanders. Syst. Appl. Microbiol. 32:211-225.

Darling, A. E., Mau, B., and Perna, N. T. 2010. progressiveMauve: Multiple genome alignment with gene gain, loss and rearrangement. PLoS ONE 5: e11147.

de Bruijn, I., de Kock, M. J. D., Yang, M., de Waard, P., van Beek, T. A., and Raaijmakers, J. M. 2007. Genome-based discovery, structure prediction and functional analysis of cyclic lipopeptide antibiotics in Pseudomonas species. Mol. Microbiol. 63:417-428.

de Bruijn, I., and Raaijmakers, J. M. 2009. Regulation of cyclic lipopeptide biosynthesis in Pseudomonas fluorescens by the ClpP protease. J. Bacteriol. 191:1910-1923.

de Zwart, F. J., Slow, S., Payne, R. J., Lever, M., George, P. M., Gerrard, J. A., and Chambers, S. T. 2003. Glycine betaine and glycine betaine analogues in common foods. Food Chem. 83:197-204.

Delcher, A. L., Harmon, D., Kasif, S., White, O., and Salzberg, S. L. 1999. Improved microbial gene identification with GLIMMER. Nucleic Acids Res. 27:4636-4641.

Dereeper, A., Guignon, V., Blanc, G., Audic, S., Buffet, S., Chevenet, F., Dufayard, J. F., Guindon, S., Lefort, V., Lescot, M., Claverie, J. M., and Gascuel, O. 2008. Phylogeny.fr: Robust phylogenetic analysis for the non-specialist. Nucleic Acids Res. 36:W465-W469.

Diab, F., Bernard, T., Bazire, A., Haras, D., Blanco, C., and Jebbar, M. 2006. Succinate-mediated catabolite repression control on the production of glycine betaine catabolic enzymes in Pseudomonas aeruginosa PAO1 under low and elevated salinities. Microbiology 152:1395-1406.

Emanuele, M. C., Scaloni, A., Lavermicocca, P., Jacobellis, N. S., Camoni, L., Di Giorgio, D., Pucci, P., Paci, M., Segre, A., and Ballio, A. 1998. Corpeptins, new bioactive lipodepsipeptides from cultures of Pseudomonas corrugata. FEBS (Fed. Eur. Biochem. Soc.) Lett. 433:317-320.

Eshoo, M. W. 1988. lac fusion analysis of the bet genes of Escherichia coli: Regulation by osmolarity, temperature, oxygen, choline, and glycine betaine. J. Bacteriol. 170:5208-5215

Feil, H., Feil, W. S., Chain, P., Larimer, F., DiBartolo, G., Copeland, A., Lykidis, A., Trong, S., Nolan, M., Goltsman, E., Thiel, J., Malfatti, S. Loper, J. E., Lapidus, A., Detter, J. C., Land, M., Richardson, P. M., Kyrpides, N. C., Ivanova, N., and Lindow, S. E. 2005. Comparison of the complete genome sequences of Pseudomonas syringae pv. syringae B728a and pv. tomato DC3000. Proc. Natl. Acad. Sci. U.S.A. 102:11064-11069.

Flamand, M. C., Pelsser, S., Ewbank, E., and Maraite, H. 1996. Production of syringotoxin and other bioactive peptides by Pseudomonas fuscovaginae. Physiol. Mol. Plant Pathol. 48:217-231.

Grgurina, I., Bensaci, M., Pocsfalvi, G., Mannina, L., Cruciani, O., Fiore, A., Fogliano, V., Sorensen, K. N., and Takemoto, J. Y. 2005. Novel cyclic lipodepsipeptide from Pseudomonas syringae pv. lachrymans strain 508 and syringopeptin antimicrobial activities. Antimicrob. Agents Chemother. 49:5037-5045.
Gross, D. C., and DeVay, J. E. 1977. Role of syringomcin in holcus spot of maize and systemic necrosis of cowpea caused by Pseudomonas syringae. Physiol. Mol. Plant Pathol. 11:1-11.

Gross, H., and Loper, J. E. 2009. Genomics of secondary metabolite production by Pseudomonas spp. Nat. Prod. Rep. 26:1408-1446.

Gross, H., Stockwell, V. O., Henkels, M. D., Nowak-Thompson, B., Loper, J. E., and Gerwick, W. H. 2007. The genomisotopic approach: A systematic method to isolate products of orphan biosynthetic gene clusters. Chem. Biol. 14:53-63.

Halliwell, B. 2006. Reactive species and antioxidants. Redox biology is a fundamental theme of aerobic life. Plant Physiol. 141:312-322.

Hoang, T. T., Karkhoff-Schweizer, R. R., Kutchma, A. J., and Schweizer, H. P. 1998. A broad-host-range Flp-FRT recombination system for sitespecific excision of chromosomally-located DNA sequences: Application for isolation of unmarked Pseudomonas aeruginosa mutants. Gene 212:77-86.

Hojo, H., Koyanagi, M., Tanaka, M., Kajihara, S., Ohnishi, K., Kiba, A., and Hikichi, Y. 2008. The hrp genes of Pseudomonas cichorii are essential for pathogenicity on eggplant but not on lettuce. Microbiology 154:2920-2928.

Hu, F. P., Young, J. M., and Fletcher, M. J. 1998. Preliminary description of biocidal (syringomycin) activity in fluorescent plant pathogenic Pseudomonas species. J. Appl. Microbiol. 85:365-371.

Hutchison, M. L., Tester, M. A., and Gross, D. C. 1995. Role of biosurfactant and ion channel-forming activities of syringomycin in transmembrane ion flux: A model for the mechanism of action in the plant-pathogen interaction. Mol. Plant Microbe Interact. 8:610-620.

Iacobellis, N. S., Lavermicocca, P., Surico, G., and Durbin, R. D. 1992. The occurrence of a syringomycin-macromolecular complex in cultures of Pseudomonas syringae pv. syringae. Physiol. Mol. Plant Pathol. 40: 91-105.

Jagger, I. C. 1914. Bacterial leaf spot disease of celery. Phytopathology 4: 395.

Jones, J. B., Raju, B. C., and Engelhard, A. W. 1984. Effects of temperature and leaf wetness on development of bacterial spot of geranium and chrysanthemum incited by Pseudomonas cichorii. Plant Dis. 68: 248-251.

Kajihara, S., Hojo, H., Koyanagi, M., Tanaka, M., Mizumoto, H., Ohnishi, K., Kiba, A., and Hikichi, Y. 2012. Implication of hrpW in virulence of Pseudomonas cichorii. Plant Pathol. 61:355-363.

Kang, H., and Gross, D. C. 2005. Characterization of a resistancenodulation-cell division transporter system associated with the syr-syp genomic island of Pseudomonas syringae pv. syringae. Appl. Environ. Microbiol. 71:5056-5065.

Kiba, A., Lee, K. Y., Ohnishi, K., Park, P., Nakayashiki, H., Tosa, Y., Mayama, S., and Hikichi, Y. 2009. Induction of reactive oxygen generation and functional changes in mitochondria and their involvement in the development of bacterial rot in lettuce caused by Pseudomonas cichorii. Physiol. Mol. Plant Pathol. 74:45-54.

Kiba, A., Sangawa, Y., Ohnishi, K., Yao, N., Park, P., Nakayashiki, H., Tosa, Y., Mayama, S., and Hikichi, Y. 2006. Induction of apoptotic cell death leads to the development of bacterial rot caused by Pseudomonas cichorii. Mol. Plant Microbe Interact. 19:112-122.

Koch, B., Nielsen, T. H., Sørensen, D., Andersen, J. B., Christophersen, C., Molin, S., Givskov, M., Sørensen, J., and Nybroe, O. 2002. Lipopeptide production in Pseudomonas sp. strain DSS73 is regulated by components of sugar beet seed exudate via the Gac two-component regulatory system. Appl. Environ. Microbiol. 68:4509-4516.

Landfald, B., and Strøm, A. R. 1986. Choline-glycine betaine pathway confers a high level of osmotic tolerance in Escherichia coli. J. Bacteriol. 165:849-855

Lavermicocca, P., Iacobellis, N. S., Simmaco, M., and Graniti, A. 1997. Biological properties and spectrum of activity of Pseudomonas syringae pv. syringae toxins. Physiol. Mol. Plant Pathol. 50:129-140.

Lazzaroni, S., Evidente, A., and Surico, G. 2003. Toxic metabolites and lipopolysaccharides from Pseudomonas cichorii. Pages 233-243 in: Pseudomonas syringae and related pathogens. N. S. Iacobellis, A. Collmer, S. W. Hutchison, J. W. Mansfield, C. E. Morris, J. Murillo, N. W. Schaad, D. E. Stead, G. Surico, and M. S. Ullrich, eds. Kluwer academic publishers, Dordrecht, The Netherlands.

Li, S., Yu, X., and Beattie, G. A. 2013. Glycine betaine catabolism contributes to Pseudomonas syringae tolerance to hyperosmotic stress by relieving betaine-mediated suppression of compatible solute synthesis. J. Bacteriol. 195:2415-2423.

Licciardello, G., Bertani, I., Steindler, L., Bella, P., Venturi, V., and Catara, V. 2009. The transcriptional activator $r f i A$ is quorum-sensing regulated by cotranscription with the luxI homolog $\mathrm{pcoI}$ and is essential for plant virulence in Pseudomonas corrugata. Mol. Plant Microbe Interact. 22:1514-1522. 
Licciardello, G., Strano, C. P., Bertani, I., Bella, P., Fiore, A., Fogliano, V., Venturi, V., and Catara, V. 2012. N-acyl-homoserine-lactone quorum sensing in tomato phytopathogenic Pseudomonas spp. is involved in the regulation of lipodepsipeptide production. J. Biotechnol. 159:274-282.

Meyer, J. M., and Abdallah, M. A. 1978. The fluorescent pigment of Pseudomonas fluorescens: Biosynthesis, purification and physicochemical properties. J. Gen. Microbiol. 107:319-328.

Mo, Y. Y., and Gross, D. C. 1991. Plant signal molecules activate the syrB gene, which is required for syringomycin production by Pseudomonas syringae pv. syringae. J. Bacteriol. 173:5784-5792.

Monti, S. M., Gallo, M., Ferracane, R., Borrelli, R. C., Ritieni, A., Greco, M. L., Graniti, A., and Fogliano, V. 2001. Analysis of bacterial lipodepsipeptides by matrix-assisted laser desorption/ionisation time-offlight and high-performance liquid chromatography with electrospray mass spectrometry. Rapid Commun. Mass Spectrom. 15:623-628.

Nielsen, T. H., and Sørensen, J. 2003. Production of cyclic lipopeptides by Pseudomonas fluorescens strains in bulk soil and in the sugar beet rhizosphere. Appl. Environ. Microbiol. 69:861-868.

Nielsen, T. H., Thrane, C., Christophersen, C., Anthoni, U., and Sørensen, J. 2000. Structure, production characteristics and fungal antagonism of tensin - a new antifungal cyclic lipopeptide from Pseudomonas fluorescens strain 96.578. J. Appl. Microbiol. 89:992-1001.

Pauwelyn, E. 2012. Epidemiology and pathogenicity mechanisms of Pseudomonas cichorii, the causal agent of midrib rot in greenhousegrown butterhead lettuce (Lactuca sativa L.). Dissertation. Ghent University, Ghent, Belgium.

Pauwelyn, E., Huang, C. J., Ongena, M., Leclère, V., Jacques, P., Bleyaert, P., Budzikiewicz, H., Schäfer, M., and Höfte, M. 2013. New linear lipopeptides produced by Pseudomonas cichorii SF1-54 are involved in virulence, swarming motility, and biofilm formation. Mol. Plant Microbe Interact. 26:585-598.

Pauwelyn, E., Vanhouteghem, K., Cottyn, B., De Vos, P., Maes, M., Bleyaert, P., and Hofte, M. 2011. Epidemiology of Pseudomonas cichorii, the case of lettuce midrib rot. J. Phytopathol. 159:298-305.

Raaijmakers, J. M., de Bruijn, I., and de Kock, M. J. D. 2006. Cyclic lipopeptide production by plant-associated Pseudomonas spp.: Diversity, activity, biosynthesis, and regulation. Mol. Plant Microbe Interact. 19:699-710.

Raaijmakers, J. M., De Bruijn, I., Nybroe, O., and Ongena, M. 2010. Natural functions of lipopeptides from Bacillus and Pseudomonas: More than surfactants and antibiotics. FEMS (Fed. Eur. Microbiol. Soc.) Microbiol. Rev. 34:1037-1062.

Rausch, C., Hoof, I., Weber, T., Wohlleben, W., and Huson, D. H. 2007. Phylogenetic analysis of condensation domains in NRPS sheds light on their functional evolution. BMC Evol. Biol. 7:78.

Rausch, C., Weber, T., Kohlbacher, O., Wohlleben, W., and Huson, D. H. 2005. Specificity prediction of adenylation domains in nonribosomal peptide synthetases (NRPS) using transductive support vector machines (TSVMs). Nucleic Acids Res. 33:5799-5808.

Röttig, M., Medema, M. H., Blin, K., Weber, T., Rausch, C., and Kohlbacher, O. 2011. NRPSpredictor2-A web server for predicting NRPS adenylation domain specificity. Nucleic Acids Res. 39:W362W367.

Sambrook, J., and Russel, D. W. 2001. Molecular cloning: A laboratory manual, 3rd Ed. Cold Spring Harbor Laboratory Press, Cold Spring Harbor, New York.
Scholz-Schroeder, B. K., Hutchison, M. L., Grgurina, I., and Gross, D. C. 2001. The contribution of syringopeptin and syringomycin to virulence of Pseudomonas syringae pv. syringae strain B301D on the basis of sypA and syrB1 biosynthesis mutant analysis. Mol. Plant Microbe Interact. 14:336-348.

Scholz-Schroeder, B. K., Soule, J. D., and Gross, D. C. 2003. The sypA, sypB, and syp $C$ synthetase genes encode twenty-two modules involved in the nonribosomal peptide synthesis of syringopeptin by Pseudomonas syringae pv. syringae B301D. Mol. Plant Microbe Interact. 16:271-280.

Shanks, R. M. Q., Caiazza, N. C., Hinsa, S. M., Toutain, C. M., and O’Toole, G. A. 2006. Saccharomyces cerevisiae-based molecular tool kit for manipulation of genes from gram-negative bacteria. Appl. Environ. Microbiol. 72:5027-5036.

Shirakawa, T., and Ozaki, K. 1993. Ultrastructural changes of lettuce tissue due to Pseudomonas cichorii and cichorin. Ann. Phytopathol. Soc. Jpn. 59:316.

Simon, R., Priefer, U., and Puhler, A. 1983. A broad host range mobilization system for in vivo genetic engineering: Transposon mutagenesis in gramnegative bacteria. Nat. Biotechnol. 1:784-791.

Stachelhaus, T., Mootz, H. D., and Marahiel, M. A. 1999. The specificityconferring code of adenylation domains in nonribosomal peptide synthetases. Chem. Biol. 6:493-505.

Velasco-García, R., González-Segura, L., and Muñoz-Clares, R. A. 2000. Steady-state kinetic mechanism of the $\mathrm{NADP}^{+}$- and $\mathrm{NAD}^{+}$-dependent reactions catalysed by betaine aldehyde dehydrogenase from Pseudomonas aeruginosa. Biochem. J. 352:675-683.

Ward, J. L., Forcat, S., Beckmann, M., Bennett, M., Miller, S. J., Baker, J. M., Hawkins, N. D., Vermeer, C. P., Lu, C., Lin, W., Truman, W. M., Beale, M. H., Draper, J., Mansfield, J. W., and Grant, M. 2010. The metabolic transition during disease following infection of Arabidopsis thaliana by Pseudomonas syringae pv. tomato. Plant J. 63:443-457.

Wargo, M. J. 2013. Homeostasis and catabolism of choline and glycine betaine: Lessons from Pseudomonas aeruginosa. Appl. Environ. Microbiol. 79:2112-2120.

Wilkie, P. J., and Dye, D. W. 1974. Pseudomonas cichorii causing tomato and celery diseases in New Zealand. N. Zeal. J. Agr. Res. 17:123-130.

Yu, S.-M., and Lee, Y. H. 2012. First report of Pseudomonas cichorii associated with leaf spot on soybean in South Korea. Plant Dis. 96:142.

Yu, X., Lund, S. P., Scott, R. A., Greenwald, J. W., Records, A. H., Nettleton, D., Lindow, S. E., Gross, D. C., and Beattie, G. A. 2013. Transcriptional responses of Pseudomonas syringae to growth in epiphytic versus apoplastic leaf sites. Proc. Natl. Acad. Sci. U.S.A. 110:E425-E434.

Zeisel, S. H., Mar, M. H., Howe, J. C., and Holden, J. M. 2003. Concentrations of choline-containing compounds and betaine in common foods. J. Nutr. 133:1302-1307.

\section{AUTHOR-RECOMMENDED INTERNET RESOURCES}

The European Bioinformatics Institute website: www.ebi.ac.uk National Institute of Immunology NRPS-PKS website: http://www.nii.res.in/nrps-pks.html

The NRPS/PKS analysis website: http://nrps.igs.umaryland.edu/nrps NRPSpredictor2: http://nrps.informatik.uni-tuebingen.de 